\title{
Aprendizado e seleção: uma análise da evolução educacional brasileira de acordo com uma perspectiva de ciclo de vida*
}

Sergei Soares

\section{Resumo}

Analisa as tendências educacionais dos últimos vinte anos, levando em conta duas características dos sistemas educacionais: a seleção e a estratificação etária. Todos os sistemas educacionais formais se dividem em ciclos que, grosso modo, correspondem a faixas etárias. Outra característica de todos os sistemas educacionais é que têm um duplo objetivo: formar e selecionar. Ao contrário do que ocorre na maioria dos outros países, há no Brasil uma forma de seleção em massa que descasa os ciclos educacionais de suas faixas etárias - a repetência. Por esta razão, o texto tenciona manter dois olhares: um por idade e outro por faixa etária. Após uma introdução resumindo a dinâmica demográfica do período, os principais indicadores analisados são: o acesso a cada nível escolar, representado pela taxa de matrícula líquida; o impacto da repetência, representado pela distorção idade-série ao final de cada ciclo; e o aprendizado, medido por avaliações padronizadas. Analisa tanto níveis como distribuição, uma vez que as desigualdades no nosso país são fortes. As principais conclusões são que, a despeito da vitória da universalização do acesso, o processo educacional ainda leva a resultados insatisfatórios em termos de médias e reproduz as desigualdades presentes na sociedade brasileira. $\mathrm{O}$ texto termina com uma série de recomendações de políticas para todos os níveis educacionais, que vão desde a universalização da pré-escola nas áreas urbanas até a adequação da oferta de educação de jovens e adultos e superior à sua demanda potencial.

Palavras-chave: demografia; seleção; repetência; sistema educacional

\section{Abstract}

Learning and selection: an analysis of the brazilian educational evolution according to perspective of the circle of life

The objective of this text is to analyze the main trends of the last 20 years keeping in mind two important characteristics of the Brazilian educational system: selection and stratification by age. All educational systems are divided into cycles that, grosso modo, correspond to age groups. In addition, all educational systems have two main objectives: teaching and selecting. A peculiarity of the Brazilian system is that its main selection mechanism, massive grade repetition, distorts the age profile of its students so that educational cycles no longer correspond to specific ages. For this reason, the text attempts

* O autor agradece os comentários de Guilherme Sedlaceck, Yuri Soares e Martha Cassiolato, além da cooperação de Ana Amélia Camarano, sem os quais este texto seria impossível. to always look at education from the points of view of both cycles and age groups. After an introduction summarizing the main demographic trend of the last 30 to 20 years, the text analyzes three types of indicator: access represented by net enrollment rates, the impacts of repetition as represented by age-grade distortion, and learning as represented by the results of standardized testing. The objective is to always analyze both means and 
dispersions, due to the strong inequality of our country. The main conclusions are that, in spite of the important educational achievement that was the universalization of access, the Brazilian educational process still leads to low attainment and achievement in levels as well as to reproduction of the inequalities present in the Brazilian society. The text ends with a series of policy challenges that go from universalization of pre-school in urban areas to the adjustment of young adult and higher education supply to their demand.

Keywords: demography; selection; repetition; educational system

\section{Introdução: a edụcação e o ciclo de vida}

O processo educativo dura a vida toda. Os seres humanos começam a aprender quando nascem e param apenas quando, devido à morte ou à senilidade, não podem mais incorporar e reorganizar conhecimento. No entanto, a forma deste processo varia de acordo com a idade dos indivíduos. Uma razão óbvia é que a capacidade dos indivíduos de aprender ou empreender atividades de aprendizagem sofre variações etárias biológicas. Mais importante é que o modo pelo qual se organizam estas atividades difere de cultura para cultura. Em algumas culturas, o aprendizado mais importante é considerado aquele adquirido pela experiência vivida, o que faz dos anciãos os indivíduos com maior conhecimento; em outras, o aprendizado é formalizado e institucionalizado de modo que aqueles que tiveram acesso a estas oportunidades são os indivíduos com maior conhecimento. Em todas as culturas, as atividades de aprendizagem convivem de modo competitivo ou complementar com as atividades produtivas e de lazer, e o tempo para cada uma depende da idade do indivíduo que as empreende.

Nas sociedades modernas, a educação foi organizada em ciclos de aprendizagem fortemente relacionados à idade. Isto ocorre não apenas por razões biológicas, mas principalmente em função de como foram organizadas as atividades cívicas, o trabalho, as responsabilidades familiares e reprodutivas, além de como é distribuído o poder em cada sociedade segundo a idade. Educação formal diurna disputa as horas do dia com a participação no mercado de trabalho e as responsabilidades familiares, fazendo com que a freqüência à escola seja mais fácil para os indivíduos que não as têm. Em resposta a isto, mesmo quando o conteúdo do aprendizado é semelhante, o processo educativo é organizado de modo diferente para indivíduos de idades diferentes.

Todas as sociedades modernas têm algum tipo de sistema de ensino formal que tanto ensina como também seleciona indivíduos de acordo com o seu sucesso em navegar esse sistema. Evidentemente, diferentes ciclos educativos enfatizam mais o aprendizado ou mais a seleção, mas ambos existem de alguma forma em todos os níveis de todos os sistemas educativos. Adicionalmente, nas sociedades modernas os resultados educacionais estão intimamente ligados às oportunidades que os indivíduos terão posteriormente em termos de renda, status, poder e os outros indivíduos com quem irá socializar. Em outras palavras, nas sociedades modernas a educação formal é um determinante fundamental do status socioeconômico.

Na maioria dos sistemas educacionais, o aprendizado formal começa antes da seleção formal. É evidente que informalmente o processo seletivo começa com a definição da instituição educacional na qual a criança se matriculará. No Brasil, o estágio educacional em que não existe seleção formal é a educação infantil. Não há repetência, e o aprendizado é, pelo menos a princípio, o único objetivo, do ponto de vista da criança, na educação infantil. A idade apropriada à educação infantil vai do nascimento aos seis anos de idade. Aos sete anos as crianças entram no ensino fundamental ou de primeiro grau, e, neste nível, uma forma forte e cruel de seleção começa a operar: a repetência. Isto continua até o ensino médio, também chamado de segundo grau, cuja idade apropriada é de 15 a 18 anos, apesar de a repetência ter distorcido a relação entre idade e série a ponto de apenas metade da matrícula nesse nível cair nesta faixa etária.

O ensino superior se abre com um novo tipo de seleção, dado que nem todos que terminam o ciclo educacional diretamente inferior têm acesso a este nível de 
ensino. Os egressos do ensino médio devem passar num exame para entrar no ensino superior, e esta é uma das transições mais difíceis e que incorpora mecanismos de seleção mais importantes no Brasil. Na mesma faixa etária da educação superior, para indivíduos acima de 18 anos e que não concluíram o ensino fundamental, é ofertada a educação de jovens e adultos, embora se perceba mais adiante que esta oferta é grosseiramente insuficiente no Brasil.

Caso não houvesse repetência, as descrições do processo educativo de acordo com a idade ou com o ciclo educativo seriam análogas. A existência de repetência quase universal faz com que isto seja muito mais difícil. Em 2003, por exemplo, a situação dos indivíduos de 15 a 18 anos era bem diferente daquilo previsto na Lei: 18\% estavam fora da escola, outros $39 \%$ estavam ainda no ensino fundamental e apenas 38\% estavam matriculados no ensino médio. Isto quer dizer que, no Brasil, a perspectiva de ciclo de vida se desdobra em duas: idade e ciclo no processo educacional. A abordagem neste texto será tratar tanto de um aspecto como do outro em cada seção. Isto quer dizer que o texto será organizado do seguinte modo:

- Educação infantil (ou de 3 a 6 anos de idade).

- Ensino fundamental (ou de 7 a 14 anos). Esta faixa de idade será subdividida em duas: de 7 a 10 anos e de 11 a 14 anos, devido ao comportamento diferente de cada uma.

- Ensino médio (ou de 15 a 18 anos).

- Educação superior e educação de jovens e adultos (ou de 18 a 25 anos).

Em cada caso, serão descritos tanto os indivíduos matriculados em cada nível de ensino como os indivíduos na faixa etária.

\section{Demografia}

Um dos mais importantes desafios de incorporação à política educacional, no passado, foi o demográfico. O crescimento populacional e o tamanho relativo de diferentes coortes populacionais

\section{Nomenclatura e organização do processo} educativo

A nomenclatura do sistema educacional brasileiro tem mudado quase continuamente ao longo das últimas décadas. Anteriormente a 1971, a educação básica era dividida em três ciclos, popularmente conhecidos como primário, ginásio e científico. A duração-padrão do primário era de quatro anos, mas em alguns casos era de cinco; o ginásio era composto de quatro séries e o científico, de outras três. O primário era obrigatório, apesar de as taxas líquidas de matrícula serem inferiores a 50\% até a década de 70, e os outros dois eram opcionais, porém obrigação do Estado.

Com a Lei n ${ }^{\circ}$ 5.692, de 11 de agosto de 1971, os dois primeiros ciclos foram fundidos em um único curso de primeiro grau, obrigatório e de duração modal de oito séries, e o terceiro ciclo foi transformado em um segundo grau de três (ou em alguns casos, quatro) séries, cuja oferta mantém-se como obrigação do Estado. A freqüência ao segundo grau continuou opcional para os indivíduos. Ou seja, a distinção entre o primeiro e segundo ciclo do sistema anterior foi apagada por lei. É claro que a realidade não foi adequadamente avisada desta mudança, e até hoje, quatro décadas depois, é comum nas áreas rurais a presença de escolas primárias com quatro ou cinco séries sem que haja qualquer escola próxima que ofereça as séries subseqüentes.

A estrutura acima é mantida até hoje, embora o primeiro grau seja chamado de ensino fundamental e o segundo, de ensino médio. O conjunto dos ensinos fundamental, médio e educação infantil (pré-escola e creche) é chamado de educação básica.

Neste esquema classificatório existe um "animal" de difícil categorização: a classe da alfabetização. Este nível intermediário nunca foi amado pelos teóricos da organização do sistema, mas até hoje ele é popular no Nordeste e no Estado do Rio de Janeiro. Trata-se de um ano entre a educação infantil e o ensino fundamental ou então um ano preparatório para o fundamental. Quando o Fundef começou a distribuir recursos para o ensino fundamental com base na matrícula no ano anterior, as classes de alfabetização não foram incluídas. A reação, previsível, de muitas redes escolares foi de considerar todos os alunos inscritos neste nível como alunos de primeira série e fazer com que todos a repetissem. Para evitar soluções esdrúxulas como esta, a classe de alfabetização passa a ser hoje considerada como o primeiro ano de um fundamental ampliado para nove anos.

O ensino superior no Brasil nunca foi um direito, tanto que existe uma prova que determina quais indivíduos podem ou não se matricular em instituições de ensino superior.

Neste texto usarei a palavra "ciclo" para referir-me a divisões do processo educativo de duração superior a um ano. Isto não tem qualquer relação com política de ciclos - uma das políticas de combate à repetência mais usadas no Brasil. 
foram fundamentais em determinar os investimentos educacionais no Brasil.

A Tabela 1 mostra dados do censo demográfico organizados por grupos etários. Nas três décadas entre 1970 e 2000, a população em idade escolar (de zero a 25) aumentou em quase 28 milhões de pessoas, e, se considerarmos a de 2000 em relação à de 1960, verificaremos que quase dobrou o tamanho deste grupo de idade. Quarenta anos é um tempo relativamente longo, mas dobrar a população em idade escolar nesse período é um aumento muito expressivo. Isto quer dizer que, apenas para acompanhar a pressão demográfica, foram exigidos recursos consideráveis. Construir novas salas de aula e treinar novos professores para acomodar cada vez mais alunos exigiu volumes consideráveis de recursos, deixando menos para ampliar a cobertura e melhorar a qualidade do ensino.

Tabela 1 - População por grupo etário (em milhões)

\begin{tabular}{|c|c|c|c|c|c|c|}
\hline Ano & $\begin{array}{c}\text { Todas as } \\
\text { Idades }\end{array}$ & $\mathbf{0 - 2 5}$ anos & $\mathbf{0 - 6}$ anos & $\mathbf{7 - 1 4}$ anos & $\mathbf{1 5 - 1 8}$ anos & $\mathbf{1 9 - 2 5}$ anos \\
\hline 1960 & 70,2 & 44,7 & 15,5 & 14,4 & 6,0 & 8,8 \\
\hline 1970 & 93,1 & 59,4 & 19,5 & 19,7 & 8,5 & 11,7 \\
\hline 1980 & 119,0 & 72,7 & 22,5 & 23,0 & 11,1 & 16,1 \\
\hline 1991 & 146,8 & 82,2 & 23,4 & 27,6 & 12,2 & 19,0 \\
\hline 1996 & 157,1 & 83,6 & 22,1 & 27,6 & 13,7 & 20,2 \\
\hline 2000 & 170,0 & 87,2 & 23,1 & 27,1 & 14,5 & 22,5 \\
\hline
\end{tabular}

Fonte: Censos Demográficos.

A Figura 1 mostra a mesma informação que a Tabela 1, destacando algumas idades simples. Cada curva corresponde a um ano censitário, e o aumento na população pode ser visualizado como a área entre as curvas sucessivas. Mostra também dois fatos com clareza. O primeiro é que a população em idade escolar aumenta a um ritmo diferente em cada grupo etário: enquanto o grupo de 7 a 14 anos sofreu aumento considerável de 1960 a 1970 e cresceu menos nas outras décadas, o grupo de 15 a 18 anos cresceu mais entre 1970 e 1980. O segundo fato é que a pressão populacional está diminuindo, embora isto seja mais sensível apenas em algumas faixas etárias. Durante a última década a população em idade escolar permaneceu estável ou até caiu nos grupos de idade até 12 anos, mas aumentou no grupo de 15 a 18 anos e ainda mais no grupo de 19 a 25 anos.

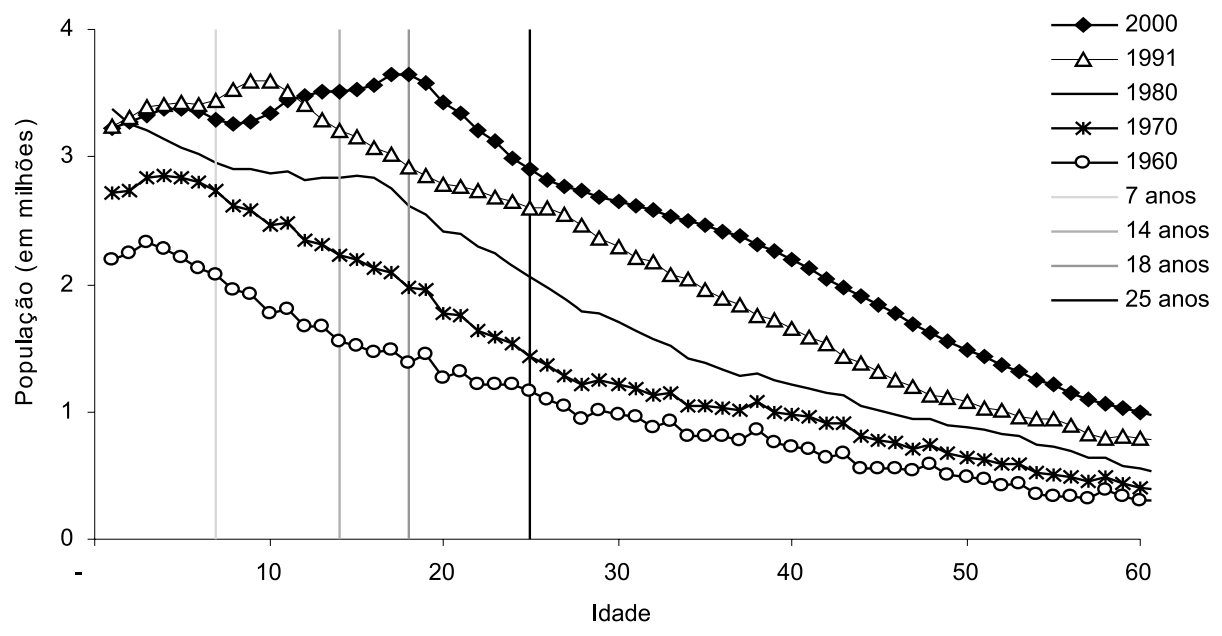

Figura 1- População por idade, em milhões de indivíduos

Fonte: Censos Demográficos cedidos por Ana Amélia Camarano. 
Qual foi a reação do sistema educacional a estes aumentos populacionais? As Tabelas 2 e 3 mostram que a resposta foi substancial, porém incompleta. De 1970 a 2000 , o Brasil criou 32 milhões de novas vagas escolares em todos os níveis, o que equivale à população da Argentina, mas, por outro lado, a Tabela 3 mostra que as taxas brutas de matrícula ${ }^{1}$ não aumentaram muito, principalmente na educação infantil e no ensino médio.
Como pode ser observado na Tabela 1, em 1970 o Brasil contava com quase 60 milhões de indivíduos com menos de 25 anos. Três décadas depois, em 2001, havia outras 27 milhões de pessoas no mesmo grupo etário. Isto quer dizer que grande parte dos 32 milhões de novas vagas nas escolas foi apenas para acompanhar o processo de crescimento populacional. Isto indica que o acesso do brasileiro médio poderia ter aumentado mais nestes 30 anos caso a pressão demográfica fosse menor.

Tabela 2 - Matrícula por ciclo (em milhões)

\begin{tabular}{|c|c|c|c|c|c|}
\hline Ano & Total & Inicial & Fundamental & Médio & Superior \\
\hline 1970 & 17,8 & 0,4 & 15,9 & 1,1 & 0,4 \\
\hline 1980 & 28,1 & 1,3 & 22,6 & 2,8 & 1,4 \\
\hline 1991 & 39,9 & 5,3 & 29,2 & 3,8 & 1,6 \\
\hline 1996 & 46,4 & 5,7 & 33,1 & 5,7 & 1,9 \\
\hline 2000 & 50,4 & 3,8 & 35,7 & 8,2 & 2,7 \\
\hline
\end{tabular}

A taxa de matrícula bruta normalmente não é um bom indicador para analisar a oferta educacional em qualquer nível. Entretanto, é útil usá-la para visualizar o desempenho agregado do sistema educacional em prover o acesso. Em outras palavras, usando as taxas de matrícula bruta, é possível decompor o crescimento na matrícula total entre aquele que meramente acompanha o crescimento demográfico e aquele que aumenta o acesso (ver Tabelas 4 e 5 ).

Tabela 3 - Taxas de matrícula bruta

\begin{tabular}{|c|c|c|c|c|c|}
\hline Ano & Total & Inicial & Fundamental & Médio & Superior \\
\hline 1970 & $30 \%$ & $2 \%$ & $81 \%$ & $13 \%$ & $4 \%$ \\
\hline 1980 & $39 \%$ & $6 \%$ & $98 \%$ & $25 \%$ & $9 \%$ \\
\hline 1991 & $48 \%$ & $23 \%$ & $106 \%$ & $31 \%$ & $8 \%$ \\
\hline 1996 & $56 \%$ & $26 \%$ & $120 \%$ & $42 \%$ & $9 \%$ \\
\hline 2000 & $58 \%$ & $17 \%$ & $132 \%$ & $57 \%$ & $12 \%$ \\
\hline
\end{tabular}

Fonte: Censos Escolar e Demográfico.

Decompor os aumentos de matrícula

${ }^{1}$ A taxa de matrícula bruta geralmente não é um bom indicador educacional, uma vez que um aumento neste indicador pode significar mais escolas ou simplesmente maior repetência. No contexto das mudanças demográficas, porém, é o indicador apropriado.

\begin{abstract}
em componentes demográficos e de melhoria de acesso é simples, usando-se a seguinte identidade:
\end{abstract}

(1) $M=m P$, onde $M$ representa a matrícula total, $m$ representa a taxa de matrícula bruta e $P$ a população do grupo etário relevante.
Usando a regra do produto, tem-se que: (2) $\Delta M=m \Delta P+P \Delta m$.

O primeiro termo, $m \Delta P$, representa os aumentos no número de matrículas que meramente acompanham o crescimento populacional; já o segundo, $P \Delta m$, mostra quanto deste crescimento contribui para levar a taxas de matrícula mais altas. $\mathrm{Na}$ 
Tabela 4, a seguir, o segundo termo, $P \Delta m$, é apresentado tanto em termos absolutos como em porcentagem do aumento de matrícula.

Para interpretar a Tabela 4, o melhor ponto de partida são os dados da Tabela 3. Se nos perguntarmos "Qual seria o crescimento nas matrículas de 1996 a 2000 necessário para que as taxas de matrícula brutas de 0 a 25 permanecessem constantes?", a resposta poderá ser encontrada multiplicando-se a taxa de matrícula bruta em 1996, 56\%, pelo aumento na população de 0 a 25 anos, que foi de 3,6 milhões de pessoas. Os dois milhões de vagas escolares resultantes desta operação representam o crescimento que seria necessário para que a taxa de matrícula bruta permanecesse constante em 56\%. É usual chamá-lo de crescimento vegetativo, apesar do fato de que ele nada tem de vegetativo e requer construção de escolas e contratação de professores. Os outros 1,9 milhão de vagas representam o componente de melhoria de acesso, que se pode chamar de crescimento que levará a maiores oportunidades educacionais para a população. Com esta decomposição trivial, é possível condensar as relações complexas entre a demografia e a matrícula em um único número para cada período e nível educacional/idade.

Tabela 4 - Decomposição do crescimento na matrícula

\begin{tabular}{|c|c|c|c|c|c|}
\hline Ano & Total & Inicial & Fundamental & Médio & Superior \\
\hline & & \multicolumn{2}{|c|}{ Crescimento da Matrícula, $\Delta M$} & & \\
\hline $1970-1980$ & 10,3 & 1,0 & 6,7 & 1,7 & 1,0 \\
\hline $1980-1991$ & 11,7 & 3,9 & 6,6 & 1,0 & 0,2 \\
\hline $1991-1996$ & 6,6 & 0,4 & 3,9 & 2,0 & 0,3 \\
\hline $1996-2000$ & 4,0 & $-1,9$ & 2,6 & 2,5 & 0,8 \\
\hline $1970-2000$ & 32,6 & 3,5 & 19,8 & 7,1 & 2,3 \\
\hline \multicolumn{6}{|c|}{ Crescimento levando a maiores oportunidades educacionais, $P \Delta m$} \\
\hline $1970-1980$ & 5,7 & 0,8 & 3,8 & 1,2 & 0,7 \\
\hline $1980-1991$ & 7,6 & 3,8 & 1,9 & 0,7 & $-0,1$ \\
\hline $1991-1996$ & 5,9 & 0,7 & 4,0 & 1,4 & 0,2 \\
\hline $1970-2000$ & 21,1 & 3,3 & 12,8 & 5,3 & 1,4 \\
\hline \multicolumn{6}{|c|}{ Crescimento vegetativo, $m \Delta P$} \\
\hline $1970-1980$ & 4,6 & 0,1 & 2,9 & 0,5 & 0,3 \\
\hline $1980-1991$ & 4,1 & 0,1 & 4,7 & 0,3 & 0,2 \\
\hline $1991-1996$ & 0,7 & $-0,3$ & 0,0 & 0,5 & 0,1 \\
\hline $1996-2000$ & 2,1 & 0,2 & $-0,6$ & 0,4 & 0,2 \\
\hline $1970-2000$ & 11,5 & 0,2 & 7,0 & 1,7 & 0,9 \\
\hline \multicolumn{6}{|c|}{ Porcentagem do Crescimento Levando a Maiores Oportunidades Educacionais } \\
\hline $1970-1980$ & $55 \%$ & $88 \%$ & $56 \%$ & $70 \%$ & $72 \%$ \\
\hline $1980-1991$ & $65 \%$ & $97 \%$ & $29 \%$ & $69 \%$ & $-31 \%$ \\
\hline $1991-1996$ & $90 \%$ & $173 \%$ & $101 \%$ & $73 \%$ & $66 \%$ \\
\hline $1996-2000$ & $48 \%$ & [112\%] & $122 \%$ & $84 \%$ & $71 \%$ \\
\hline $1970-2000$ & $65 \%$ & $96 \%$ & $65 \%$ & $76 \%$ & $62 \%$ \\
\hline
\end{tabular}

Fonte: Censos Escolar e Demográfico. 
O principal resultado é que, apesar do crescimento populacional rápido, houve um crescimento das oportunidades educacionais, embora partindo de uma base inicial baixa, uma vez que as taxas de matrícula eram bastante baixas em 1970. Antes de cantar os louros do esforço educacional brasileiro, é bom lembrar que outros países tiveram maior êxito em colocar todas as crianças na escola, inclusive países com grandes populações, como, por exemplo, o México. Apenas dois terços dos 32 milhões de vagas escolares acrescentadas de 1970 a 2000 foi para oferecer maiores oportunidades educacionais aos brasileiros, sendo o restante para acompanhar o crescimento populacional.

Este resultado de dois terços, entretanto, não se mantém quando se analisam distintos períodos ou níveis escolares. Por exemplo, tanto no ensino fundamental como no médio, o período de 1996 a 2000 foi aquele no qual o acesso mais aumentou. Os números mostram que, apesar do aumento rápido na população de 15 a 18 anos, $84 \%$ do aumento neste período resultou em maior acesso.

No caso do nível fundamental, o grupo de idade relevante perdeu população de 1996 a 2000. Ou seja, para manter as taxas de matrícula constantes, a matrícula total teria que cair em 300 mil vagas. $\mathrm{O}$ que ocorreu foi que cada uma dos 2,5 milhões de vagas criadas contribuiu para melhorar o acesso, além das 300 mil não perdidas (é por isso que a percentagem na Tabela 4 é de 101\%). Neste caso, a demografia operou a favor do sistema educacional, embora isto não reduza a importância da conquista do acesso quase universal no ensino fundamental.

Dois resultados excepcionais merecem destaque. No ensino superior, entre 1980 e 1991, o crescimento observado foi inferior ao vegetativo, o que quer dizer que o crescimento levando a maiores oportunidades educacionais foi negativo. Já o resultado de decomposição da educação inicial no período de 1996 a 2000 é uma aberração da metodologia. Como houve queda na matrícula de 1996 a 2000, mesmo diante de um pequeno aumento do grupo populacional, o resultado de decomposição que leva a maiores oportunidades educacionais aparece como positivo e maior que um. Pode-se desconsiderar este resultado.

\section{As perguntas da Pnad e do Censo Educacional}

As duas fontes de dados anuais com informações sobre matrícula no Brasil são o Censo Educacional e a Pesquisa Nacional por Amostra de Domicílios (Pnad). Trataremos de cada uma a seguir. O Censo Educacional, a rigor, não é um Censo e sim um registro administrativo onde a unidade de análise é a escola, preenchido por diretores escolares todos os anos. O Censo Educacional provê informações acuradas e bastante detalhadas sobre aspectos físicos e administrativos das escolas. Adicionalmente o Censo Escolar é a fonte oficial de matrículas para o cálculo dos repasses do Fundef para Estados e municípios. Portanto, este dado é colhido com bastante cuidado. Os dados do Censo são relativos à matrícula no final de março. A razão da escolha desta data é que os alunos já teriam tido tempo para decidir em qual escola vão se matricular e as incertezas de início de ano letivo já teriam acabado. Por outro lado, o tempo decorrido não terá sido suficiente para que haja perdas grandes devido ao abandono escolar. Uma conseqüência disso é que se mede a matrícula no meio do processo educativo, antes dos resultados finais em termos de transferências para outras escolas, abandono, aprovação e reprovação. A solução dada é que os resultados finais de um dado ano são coletados no Censo Escolar do ano seguinte. Deste modo, a taxa de reprovação de 2003 é conhecida apenas em 2004. Dado que são eventos referentes ao ano anterior, é provável que sejam coletados com menor exatidão que os dados de matrícula. Sendo a unidade de análise a escola, o Censo Escolar não segue alunos, e, por isso, as estimativas de repetência e evasão escolar são inexatas. A partir de 2006, pretende-se implementar o Censo por aluno. Esta é uma tarefa ambiciosa cujos muitos benefícios mais que compensam os custos mais elevados de coleta.

A Pesquisa Nacional por Amostra de Domicílios (Pnad) é uma pesquisa anual amostral com duas unidades de análise: o domicílio e o indivíduo. A cada uma destas unidades corresponde um questionário diferente cujos dados são coletados durante o mês de setembro. São aproximadamente 400 mil indivíduos em 100 mil domicílios que representam todo o Brasil, salvo, até 2003, a área rural da Região Norte, onde as grandes distâncias comprometiam este esforço. A partir de 2004, os dados dessa área rural passaram a ser coletados.

A Pnad coleta informações detalhadas sobre demografia, migração, o mercado de trabalho e nível educacional e freqüência à escola. Sendo ela uma pesquisa onde quem responde é o responsável pelo domicílio, é possível que os entrevistados não interpretem a pergunta sobre freqüência à escola como freqüência à mesma e sim como matrícula na escola. O fato de a Pnad, quase que invariavelmente, apresentar resultados de freqüência superiores aos números de matrícula do Censo Escolar, quando deveriam ser menores por sofrer abandono escolar, sugere que as famílias interpretam a pergunta sobre freqüência como matrícula. Neste trabalho, esta será a hipótese feita. 
Na educação superior as taxas de matrícula permanecem muito baixas, cerca de $12 \%$ da população de 19 a 25 anos, apesar de a maioria do aumento de vagas no passado ter levado à maior oferta.

Uma vez claro o contexto demográfico no qual o sistema educacional evoluiu, o próximo passo é analisar a evolução de cada nível e faixa etária. A próxima seção trata da educação inicial.

\section{Educação inicial para crianças de 0 a 6 anos}

Tanto na literatura internacional como na nacional, existe ampla evidência da importância da educação inicial nos resultados socioeconômicos posteriores. Por exemplo, Barros e Mendonça (1999) usam a Pesquisa de Padrões de Vida para mostrar que o acesso à préescola é um determinante positivo e significativo tanto do nível educacional alcançado como dos rendimentos no mercado de trabalho, mesmo após controlar a origem socioeconômica da criança.

Conforme afirmei acima, este texto parte do princípio de que a educação começa com o nascimento, e sabe-se que, freqüentemente, a educação formal começa pouco depois. Entretanto, como as informações sobre a freqüência à escola das crianças de idade inferior a três anos existem apenas de 1995 em diante, esta análise será feita apenas para o período 1995-2004. O texto também trata apenas de acesso, uma vez que dados de qualidade não existem para este grupo de idade.

\section{Acesso à educação inicial}

A Tabela 5 mostra um aumento contínuo, embora um tanto lento, da taxa de matrícula líquida de crianças de três a seis anos. Em 2004, apenas $61 \%$ das crianças brasileiras de três a seis estavam freqüentando a escola. Este resultado não é excepcionalmente baixo, considerando os padrões de países em desenvolvimento. Entretanto, dados tanto a importância da educação infantil nos resultados posteriores como o fato de o Brasil ser um país onde as desigualdades sociais já se fazem presentes muito cedo no desenvolvimento das crianças, este número é inaceitavelmente baixo.

Tabela 5 - Taxa líquida de matrícula de zero a seis anos

\begin{tabular}{|c|c|c|c|}
\hline Ano & 0 a 6 & 3 a 6 & 0 a 2 \\
\hline 1995 & $28 \%$ & $45 \%$ & $4.1 \%$ \\
\hline 1996 & $28 \%$ & $45 \%$ & $4.0 \%$ \\
\hline 1997 & $29 \%$ & $47 \%$ & $4.3 \%$ \\
\hline 1998 & $30 \%$ & $48 \%$ & $4.4 \%$ \\
\hline 1999 & $32 \%$ & $51 \%$ & $4,8 \%$ \\
\hline 2001 & $35 \%$ & $56 \%$ & $5,7 \%$ \\
\hline 2002 & $37 \%$ & $57 \%$ & $6,3 \%$ \\
\hline 2003 & $38 \%$ & $58 \%$ & $6,1 \%$ \\
\hline 2004 & $41 \%$ & $61 \%$ & $7,7 \%$ \\
\hline Fonte: Pnads & & & \\
\hline
\end{tabular}

A matrícula na educação infantil também sofre fortes diferenças de acordo com as diferentes divisões da sociedade brasileira e varia de acordo com grupo de renda, região e cor da pele. A Figura 2 mostra que, particularmente com relação à renda, o acesso à educação infantil é muito desigual: enquanto $81 \%$ das crianças de três a seis anos pertencentes ao quinto de maior renda domiciliar per capita estavam em instituições de ensino, apenas $53 \%$ das pertencentes ao quinto de menor renda também nelas estavam.

O lado bom da notícia é que, de 1995 a 2004, o acesso à educação infantil no quinto mais pobre aumentou em 20 pontos 
percentuais contra 10 no quinto mais rico. A diferença entre brancos e negros também vem caindo de quase seis pontos percentuais em 1995 para menos de três em 2004. Em outras palavras, o acesso à educação infantil revela um mecanismo de perpetuação das desigualdades no Brasil, que felizmente vem se atenuando.
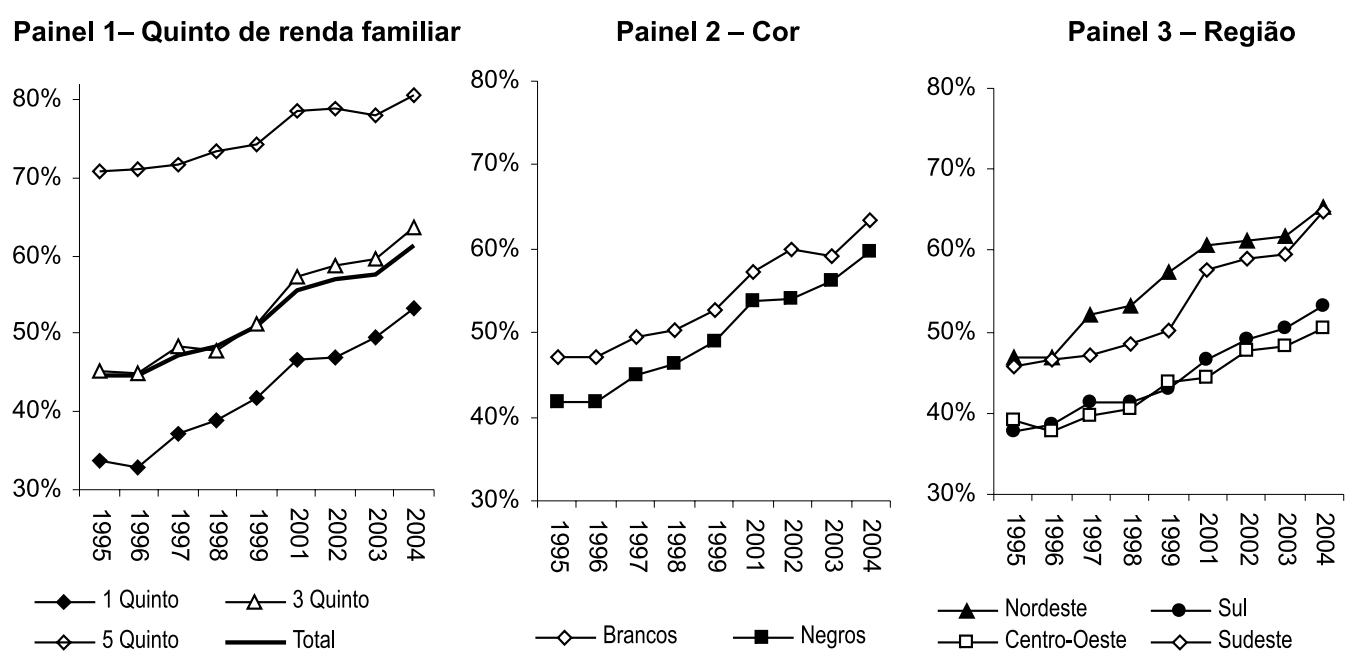

Figura 2 - Porcentagem das crianças de três a seis anos matriculadas em algum nível de ensino

Fonte: Pnads.

A Figura 3 mostra que as diferenças por quinto de renda para o grupo de idade de zero a dois anos são maiores que para as crianças de três a seis. As diferenças por cor/raça permanecem mais ou menos as mesmas. Deve-se ressaltar que não existe o mesmo consenso com relação à importância da escolarização de zero a dois anos como o que existe para a de três a seis.

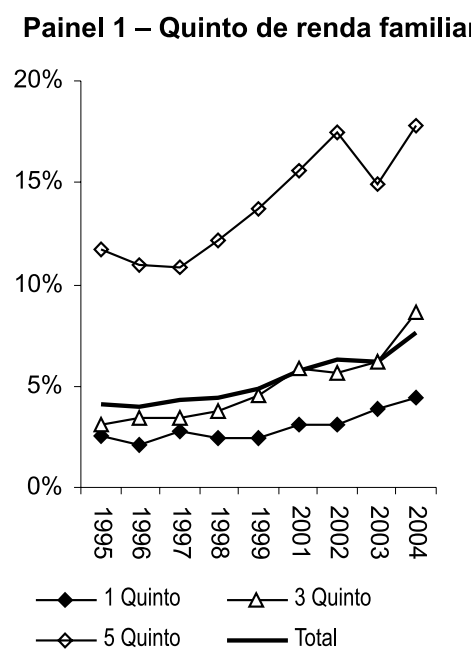

Painel 2 - Cor

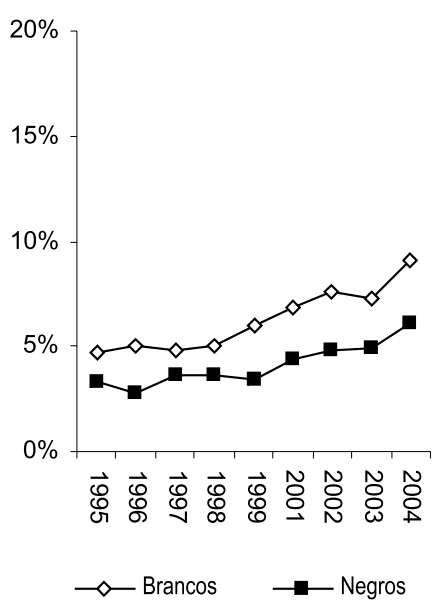

Painel 3 - Região

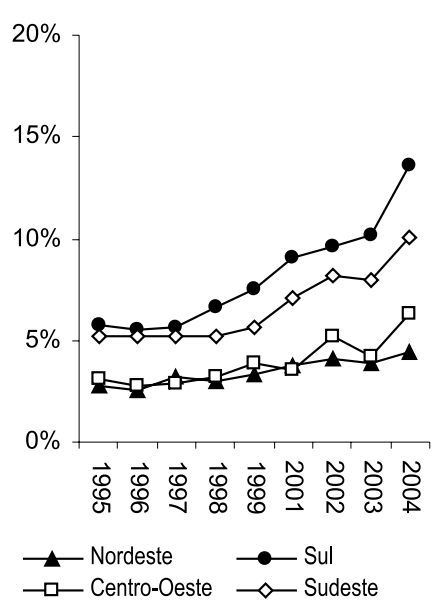

Figura 3 - Porcentagem das crianças de zero a dois anos matriculadas em algum nível de ensino 
Os resultados por região parecem, à primeira vista, contraditórios. As taxas de três a seis anos mais altas se encontram na Região Nordeste, que, como será visto mais adiante, apresenta os piores resultados educacionais em todos os outros indicadores. Atrás dela encontram-se a Região Sudeste, que é a mais rica, e a Região Sul, que em outros indicadores é a melhor, pouco acima da Região Centro-Oeste. Já de zero a dois anos é a Região Sul onde o acesso é mais alto e a Região Nordeste tem os níveis de acesso mais baixos.

A Figura 4 mostra que a diferença entre as Regiões Nordeste e Sul depende da idade. Nas idades zero, um e dois, que correspondem às idades que demandam creches, associadas mais à demanda social de mães que trabalham do que a conceitos sobre a melhor maneira de organizar o processo educativo, o Sul tem matrícula maior que o Nordeste. A partir dos três anos, que corresponde ao início da pré-escola, a Região Nordeste toma a dianteira. A maior diferença ocorre aos cinco anos de idade e provavelmente corresponde à classe de alfabetização, muito comum no Nordeste e no Rio de Janeiro e quase desconhecida em outras partes do Brasil.

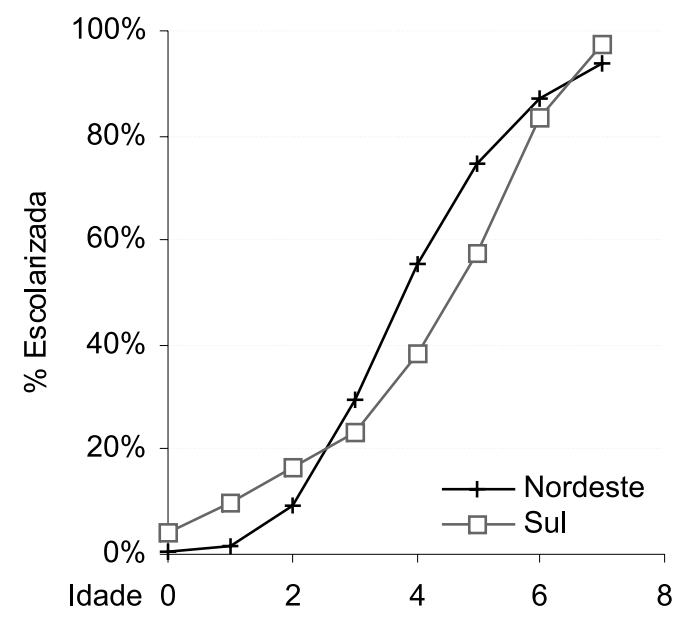

Figura 4 - Escolarização por idade nas Regiões Sul e Nordeste Fonte: Pnad 2003.

\section{Condições materiais da educação infantil}

A literatura sobre os determinantes do sucesso educacional, tanto a do Brasil como a internacional, encontra relações tênues entre insumos e resultados em todos os níveis. Isto não quer dizer que não se devam usar informações sobre insumos, apenas que não representam qualidade. Infelizmente, no Brasil, a educação infantil é a única sem avaliações anuais ou semianuais de qualidade. Por isso apresentarei aqui dados sobre insumos como indicadores de qualidade.

Em 2003, cinco milhões de crianças se matricularam em 94 mil pré-escolas e outro 1,2 milhão, em 28 mil creches. Isto mostra que o tamanho médio dos estabelecimentos não é grande: 54 crianças por pré-escola e 44 por creche. A Tabela 6 também mostra que as instituições de educação infantil não estavam muito bem equipadas para atender sua clientela com qualidade. Apenas um terço dos estabelecimentos tinha bibliotecas, apenas um em quatro tinha uma sala de brincar e o único espaço educacional presente na maioria dos estabelecimentos era um gramado. Em termos de material pedagógico os estabelecimentos estavam um pouco melhor equipados: metade tinha livros-texto, dois terços tinham algum tipo de brinquedo e três quartos, algum tipo de jogo didático. 
Tabela 6 - Porcentagem das pré-escolas e creches com vários tipos de equipamento e espaços educacionais

\begin{tabular}{|l|c|}
\hline \multicolumn{1}{|c|}{ Espaços Educacionais } & $\%$ \\
\hline Sala de brincar interna & 23,9 \\
\hline Sala de artes & 10,5 \\
\hline Biblioteca & 30,2 \\
\hline Gramado & 62,5 \\
\hline Parque infantil & 36,8 \\
\hline Solário & 7,6 \\
\hline \multicolumn{1}{|c|}{ Material Pedagógico } & $\%$ \\
\hline Brinquedos & 61,4 \\
\hline Jogos didáticos & 75,2 \\
\hline Material de Expressão Artística & 55,7 \\
\hline Livros texto & 53,8 \\
\hline Outros livros & 63,7 \\
\hline Material de Educação Física & 40,3 \\
\hline Papel e lápis & 93,0 \\
\hline
\end{tabular}

Fonte: Censo Escolar de 2002 - Suplemento de Educação Infantil.

As condições relativamente precárias das creches e pré-escolas no Brasil refletem dois fatores: o primeiro, mais geral, revela as condições precárias da educação básica pública no Brasil; o segundo, mais específico, é que até recentemente o ensino infantil não se constituía prioridade no sistema educacional brasileiro. A expansão da cobertura do ensino para as crianças com menos de sete anos e a melhoria da sua qualidade permanecem como dois dos maiores desafios neste início de milênio.

\section{O ensino fundamental}

O ensino fundamental tem imensa importância no sistema educacional brasileiro. Além de ser o único ciclo obrigatório por lei, 34 milhões de crianças matriculadas neste nível de ensino representam $57 \%$ da matrícula em todos os níveis no Brasil. Os recursos públicos destinados ao ensino fundamental representam $60 \%$ do financiamento público da educação no Brasil.

\section{Onde estão as crianças de 7 a 14 anos?}

A imensa maioria das crianças de 7 a 14 anos se encontra matriculada na escola: de acordo com a Pnad 2003, 97,2\% estão freqüentando algum nível de ensino. ${ }^{2}$ Isto quer dizer que a batalha do acesso à educação fundamental está essencialmente ganha, embora algumas frentes, como no caso de crianças com necessidades especiais, ainda permaneçam abertas.

Além de estarem quase todas na escola, poucas crianças de 7 a 14 anos participam do mercado de trabalho. A Tabela 7 mostra que a grande maioria dessas crianças se encontra freqüentando a escola $(97,2 \%)$ e fora do mercado de trabalho (90,8\%). A maioria dos 2,8\% que não estão na escola se encontra também fora do mercado de trabalho, o que sugere que fatores como escolas inadequadas a crianças com necessidades especiais sejam mais importantes do que o trabalho infantil como freios à escolarização universal; ou seja, o trabalho e sua procura não são mais determinantes importantes da freqüência à escola para a maioria das crianças 
brasileiras. Evidentemente, há situações pontuais nas quais as crianças são submetidas a trabalho em condições perigosas, insalubres ou degradantes, que são um obstáculo tanto aos resultados educacionais como até à própria vida, mas estas situações não são a norma e sim exceções.

É importante dividir as crianças de 7 a 14 anos em dois grupos de idade: de 7 a 10 e de 11 a 14. Esta divisão mostra que, embora existam poucas diferenças na porcentagem que freqüenta a escola, que cai menos de um ponto percentual, as duas faixas etárias mostram grandes diferenças na adesão ao mercado de trabalho, pois esta aumenta 12 pontos na segunda faixa. É importante ressaltar que nem para as crianças de 11 a 14 anos, $15 \%$ das quais trabalham ou procuram trabalho, o trabalho interfere de modo forte na freqüência à escola, uma vez que $92 \%$ das crianças que trabalham também freqüentam a escola. Isto não quer dizer, é claro, que a participação no mercado de trabalho não tenha efeitos deletérios sobre o desempenho escolar.

Uma vez na escola, as crianças devem progredir. Onde estão as crianças de 7 a 14 anos, considerando o processo educativo? A Tabela 8 mostra que algumas poucas $(2,2 \%)$ crianças se encontram ainda na préescola e que outras poucas $(0,3 \%)$ já se encontram na educação média. Um fato preocupante é que pouquíssimas $(0,5 \%)$ se encontram na educação especial, seja em escolas especiais ou em classes especiais dentro de escolas regulares. Este fato reforça a possibilidade de que muitas das $2,9 \%$ das crianças fora da escola são portadoras de necessidades especiais sem oferta adequada.

Tabela 7 - Crianças de 7 a 14 anos por freqüência à escola e participação no mercado de trabalho

\begin{tabular}{|l|c|c|c|}
\hline \multicolumn{1}{|c|}{ De 7 a 10} & Na Escola & Fora da Escola & Total \\
\hline No Mercado de Trabalho & $3,2 \%$ & $0,1 \%$ & $3,2 \%$ \\
\hline Fora do Mercado de Trabalho & $94,4 \%$ & $2,3 \%$ & $96,8 \%$ \\
\hline Total & $\mathbf{9 7 , 6 \%}$ & $\mathbf{2 , 4} \%$ & $\mathbf{1 0 0 , 0} \%$ \\
\hline De 11 a 14 & Na Escola & Fora da Escola & Total \\
\hline No Mercado de Trabalho & $14,2 \%$ & $1,1 \%$ & $15,3 \%$ \\
\hline Fora do Mercado de Trabalho & $82,6 \%$ & $2,1 \%$ & $84,7 \%$ \\
\hline Total & $\mathbf{9 6 , 8} \%$ & $\mathbf{3 , 2} \%$ & $\mathbf{1 0 0 , 0} \%$ \\
\hline De 7 a 14 & Na Escola & Fora da Escola & Total \\
\hline No Mercado de Trabalho & $8,6 \%$ & $0,6 \%$ & $9,2 \%$ \\
\hline Fora do Mercado de Trabalho & $88,6 \%$ & $2,2 \%$ & $90,8 \%$ \\
\hline Total & $\mathbf{9 7 , 2} \%$ & $\mathbf{2 , 8} \%$ & $\mathbf{1 0 0 , 0} \%$ \\
\hline
\end{tabular}

Fonte: Pnad 2003.

Tabela 8 - Crianças de 7 a 14 anos, por nível de freqüência à escola

\begin{tabular}{|l|c|c|c|}
\hline \multicolumn{1}{|c|}{ Nível } & De 7 a 10 & De 11 a 14 & De 7 a 14 \\
\hline Educação Infantil e CA & $4,4 \%$ & $0,0 \%$ & $2,2 \%$ \\
\hline Ensino Fundamental (de $1^{\mathrm{a}}$ a $4^{\mathrm{a}}$ série) & $92,0 \%$ & $28,6 \%$ & $60,2 \%$ \\
\hline Ensino Fundamental (de $5^{\mathrm{a}}$ a $8^{\mathrm{a}}$ série) & $1,1 \%$ & $67,6 \%$ & $33,7 \%$ \\
\hline Ensino Médio & $0,0 \%$ & $0,5 \%$ & $0,3 \%$ \\
\hline Educação Especial & $0,0 \%$ & $0,0 \%$ & $0,5 \%$ \\
\hline EJA & $0,0 \%$ & $0,0 \%$ & $0,2 \%$ \\
\hline Fora da Escola & $2,4 \%$ & $3,2 \%$ & $2,9 \%$ \\
\hline \multicolumn{1}{|c|}{ Total } & $\mathbf{1 0 0 , 0 \%}$ & $\mathbf{1 0 0 , 0 \%}$ & $\mathbf{1 0 0 , 0 \%}$ \\
\hline
\end{tabular}

Fonte: Censo Escolar 2004 e Pnad 2003. 
Fora isso, o que a Tabela 8 mostra com clareza é que já na faixa de 11 a 14 anos a repetência começa a distorcer a idade dos alunos relativamente ao desejável. Se o fluxo fosse perfeito, todos os alunos nesta faixa etária deveriam estar matriculados no segundo ciclo de $5^{\mathrm{a}}$ a $8^{\mathrm{a}}$ série, mas quase $29 \%$ ainda estão no primeiro ciclo. Outro sinal disso é que, apesar da coorte de 7 a 10 anos ser $2 \%$ menor que a coorte de 11 a 15 anos, a matrícula de 7 a 14 nos primeiros quatro anos do ensino fundamental é aproximadamente o dobro da matrícula nos últimos quatro.

\section{Taxas líquidas de matrícula}

A informação contida nas taxas de matricula líquida é limitada, uma vez que elas nada dizem sobre a eficiência do sistema em levar as crianças de uma série à próxima nem sobre o aprendizado. As taxas líquidas indicam apenas se as crianças freqüentam as escolas que deveriam freqüentar. Taxas de matrícula baixas podem indicar que muitas crianças não têm acesso à escola, embora este não seja o caso no Brasil. Podem igualmente indicar que as crianças são, por alguma razão, incapazes de progredir de uma série à próxima. É isto que ocorre no Brasil.

Tabela 9 - Taxas de matrícula líquida, segundo grupos de idade

\begin{tabular}{|c|c|c|c|}
\hline \multirow{2}{*}{ Ano } & \multicolumn{2}{|c|}{ Fundamental } & \multirow{2}{*}{$\begin{array}{c}\text { Médio } \\
\text { (de } 15 \text { a } 17 \text { anos) }\end{array}$} \\
\hline & $1^{a}$ a $4^{a}$ (de 7 a 10 anos) & $5^{\mathrm{a}}$ a $8^{\mathrm{a}}$ (de 11 a 14 anos) & \\
\hline 1981 & $74 \%$ & $31 \%$ & $15 \%$ \\
\hline 1985 & $83 \%$ & $34 \%$ & $15 \%$ \\
\hline 1990 & $86 \%$ & $40 \%$ & $17 \%$ \\
\hline 1995 & $92 \%$ & $50 \%$ & $24 \%$ \\
\hline 1999 & $97 \%$ & $62 \%$ & $35 \%$ \\
\hline 2003 & $98 \%$ & $73 \%$ & $44 \%$ \\
\hline 2004 & $98 \%$ & $74 \%$ & $46 \%$ \\
\hline
\end{tabular}

Tanto a Tabela 9 como a Figura 5 mostram as taxas de matrícula líquida durante as últimas duas décadas. Enquanto o acesso da $1^{\mathrm{a}}$ à $4^{\mathrm{a}}$ série se revela como um problema em grande medida resolvido, o acesso da $5^{\mathrm{a}}$ à $8^{\mathrm{a}}$ série ainda não o é. Apenas $74 \%$ das crianças de 11 a 14 anos estão matriculadas no segundo ciclo do fundamental. É importante ressaltar que, segundo a Constituição, a freqüência ao fundamental completo é obrigatória.

O que está gerando essa situação? Se as crianças se matriculam aos sete anos, como indica a taxa do primeiro ciclo, por que não estão no nível educacional onde deveriam estar os de 11 aos 14 anos? Parte da explicação é uma descontinuidade na oferta educativa entre a $4^{\mathrm{a}}$ e a $5^{\mathrm{a}}$ séries, principalmente na área rural. Oitenta e cinco em cada cem (85\%) escolas rurais oferecem exclusivamente da $1^{\mathrm{a}}$ à $4^{\mathrm{a}}$ série. Apesar de serem escolas pequenas que congregam menos do que dois milhões dos
4,5 milhões de crianças matriculadas em escolas rurais, muitas se apresentam como a única alternativa de ensino viável para os meninos e as meninas da área rural, que, após a conclusão de $4^{\mathrm{a}}$ série, não têm mais onde estudar. Ou seja, existe um problema de oferta adequada nas áreas rurais.

A Tabela 9 também mostra que a queda entre o primeiro e segundo ciclo do ensino fundamental é de 24 pontos percentuais As crianças rurais em escolas sem o segundo ciclo do ensino fundamental constituem menos de $8 \%$ dos 17 milhões de crianças matriculadas na escola fundamental no Brasil. Mesmo que nenhuma delas consiga passar ao próximo ciclo, restam 17 pontos percentuais de diferença entre a matrícula líquida dos dois ciclos. Duas outras explicações podem ser colocadas.

A primeira é que o trabalho infantil e condições socioeconômicas das famílias façam com que os alunos saiam da escola para ajudar no orçamento familiar. 
Embora esta seja uma razão válida, a maior parte das pesquisas sobre este tema mostra que nem as crianças nem seus pais desejam que elas ingressem na vida com uma baixa escolarização. Cavalieri (2002) e Paes de Barros et al. (2001), entre outros, mostram que o trabalho tem impactos negativos sobre a escolarização, mas que tais impactos são modestos comparados com os de outros fatores. Mais uma vez cabe enfatizar que existem situações, tais como trabalho nas plantações de cana-de- açúcar ou nas carvoarias, nas quais o impacto do trabalho de crianças é altamente negativo não apenas para a trajetória escolar, como, também, para a própria saúde - mas estas situações são minoritárias.

A segunda possibilidade é a repetência. A repetência faz com que as crianças retidas em um ano ou mais não entrem no segundo ciclo na idade apropriada, não sendo, deste modo, contabilizadas nas taxas de matrícula líquida; mais grave, as repetências múltiplas fazem com que as crianças percam a motivação e acabem saindo da escola. Autores como Ribeiro (1993), Klein (1995) e Fletcher (1997) mostram que a evasão escolar ocorre apenas após repetências múltiplas. Neste texto, esta interpretação será confirmada mediante diagramas de fase, apresentados adiante.

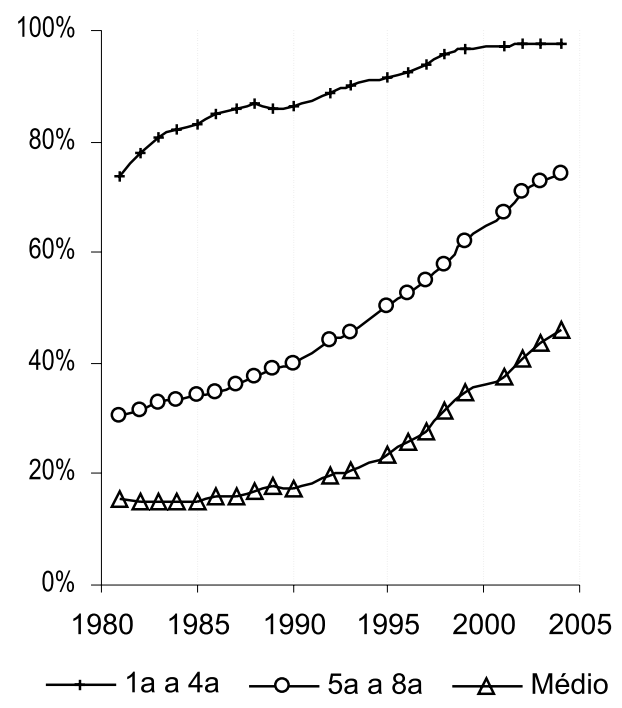

Figura 5 - Taxas de matrícula líquida por nível de ensino

Fonte: Pnads.

Do lado positivo, a Figura 5 mostra que as taxas de matrícula líquida estão aumentando em todos os níveis. Os aumentos de
1990 em diante são especialmente visíveis: a taxa de matrícula no ensino médio aumentou de 15\% em 1981 até 17\% em 1990 - apenas dois pontos percentuais em dez anos. Já de 1990 a 2001 a mesma taxa aumentou de $17 \%$ para $38 \%$, chegando a $46 \%$ em 2004 . A matrícula líquida de $5^{\mathrm{a}}$ a $8^{\mathrm{a}}$ série seguiu uma trajetória semelhante: de 31\% em 1981, 40\% em 1990, 62\% em 2001 até, finalmente 74\% em 2004. A impressão é de que, a partir de 1990, o Brasil tenta recuperar as séries perdidas nas décadas anteriores.

Os aumentos na taxa de matrícula também apontam em direção aos problemas que confrontarão o sistema educacional nos anos vindouros. A passagem de coortes cada vez mais numerosas através das séries inferiores aumentará drasticamente a pressão sobre as séries superiores. Em outras palavras, o Brasil terá de enfrentar o desafio de rapidamente adaptar ou criar cinco milhões de vagas de $5^{\mathrm{a}} \mathrm{a}$ $8^{\mathrm{a}}$ série do ensino fundamental.

\section{Eficiência e eqüidade}

Vimos até este ponto que a repetência é um dos maiores problemas enfrentados pela educação no Brasil, mas ainda não foram mostrados os números que a caracterizam. Uma das razões é que o cálculo da repetência não é trivial. O Censo Escolar reporta a reprovação e o abandono escolar referentes ao ano anterior. Esses números, entretanto, são conceitualmente diferentes da repetência e da evasão. Um aluno repete o ano se está matriculado na mesma série do mesmo grau dois anos em seguida, e um aluno sofre evasão do sistema escolar se está matriculado em um ano, mas não no seguinte; já aprovação e abandono se referem a classificações formais outorgadas pela escola a cada um de seus alunos. Em particular, grande parte do abandono escolar consiste em repetência, uma vez que representa alunos que abandonam uma tentativa de passar de ano, freqüentemente incentivados pelos professores, para matricular-se novamente na mesma série no ano seguinte. Adicionalmente, até as estatísticas de reprovação e abandono são coletadas com erro considerável, uma vez que são perguntadas mais de seis meses após o fato gerador, que ocorreu em outro ano letivo.

Pelas razões acima expostas, a repetência tem que ser calculada usando-se 
métodos indiretos que usam modelos estatísticos sujeitos a erro aleatório, e houve no Brasil intenso debate sobre qual é o melhor modelo para o cálculo dessas estatísticas fundamentais. Em termos gerais, há uma concordância entre os vários modelos: a repetência é muito maior que a reprovação, e a evasão, muito inferior ao abandono; e as crianças abandonam o sistema escolar apenas após repetir múltiplas vezes. Entretanto, como os números produzidos não são idênticos, há uma escolha a ser feita, e eu escolhi os números oficiais do Ministério da Educação, calculados a partir da metodologia de Klein (1995) e reportados na Tabela 10.

A Tabela 10 mostra as taxas de: (i) progressão, definida como alunos matriculados na série $s$ no ano $t$ e na série $s+1$ no ano $t+1$ sobre os alunos matriculados em $s$ no ano $t$; (ii) repetência, definida como alunos matriculados em $s$ no ano $t+1$ sobre matriculados em $s$ em $t$; (iii) evasão, definida como alunos não matriculados no ano $t+1$ sobre matriculados em $s$ em $t$.

Uma taxa de progressão de $73 \%$ observada no ensino fundamental em 2000 pode não parecer tão baixa, mas é o parâmetro regente de um processo iterativo. Se a cada ano apenas 73 de cada cem alunos progridem à próxima série, isto quer dizer que apenas oito de cada cem crianças que iniciaram o ensino fundamental o terminam sem repetir! A esta taxa, 14 terminarão com uma repetência e outros 34 se arrastarão até o final do fundamental após múltiplas repetências. Os 44 restantes jamais terminarão as oito séries do ensino fundamental, exauridos por um sistema escolar construído para barrar e não educar. Ou seja, uma taxa de progressão de $73 \%$ é um desastre educacional e uma crueldade humana com nossas crianças.

Se as taxas de progressão aumentassem até $80 \%, 17$ de cada cem alunos terminariam sem repetir, 22 terminariam com uma repetência, 32, com repetências múltiplas, e apenas 29 jamais terminariam. Ou seja, um aumento de sete pontos percentuais levaria a um aumento de quinze pontos percentuais na taxa de término. Apesar do processo não ser linear, pode-se dizer que, na vizinhança da taxa observada no Brasil, um aumento de um ponto percentual na taxa de progressão eleva a proporção de alunos terminando o ensino fundamental em dois pontos. ${ }^{3}$

Tabela 10 - Taxas de fluxo médias (em \%)

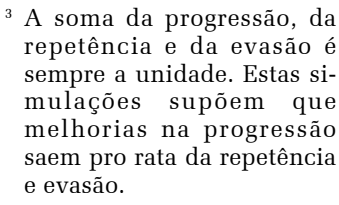

${ }^{3}$ A soma da progressão, da repetência e da evasão é sempre a unidade. Estas simulações supõem que melhorias na progressão saem pro rata da repetência e evasão.

\begin{tabular}{|c|c|c|c|c|}
\hline Ano & Progressão & Repetência & Evasão \\
\hline \multicolumn{4}{|c|}{ Ensino } & Fundamental \\
\hline 1985 & 58 & 36 & 6 \\
\hline 1990 & 60 & 34 & 6 \\
\hline 1991 & 60 & 33 & 6 \\
\hline 1994 & 64 & 30 & 5 \\
\hline 1995 & 65 & 31 & 4 \\
\hline 1996 & 69 & 27 & 5 \\
\hline 1997 & 73 & 23 & 4 \\
\hline 1998 & 74 & 21 & 5 \\
\hline 1999 & 74 & 22 & 5 \\
\hline 2000 & 73 & 22 & 5 \\
\hline & Ensino Médio & \\
\hline 1991 & 63 & 31 & 6 \\
\hline 1994 & 67 & 27 & 7 \\
\hline 1996 & 72 & 23 & 5 \\
\hline 1997 & 74 & 19 & 7 \\
\hline 1998 & 77 & 17 & 6 \\
\hline 1999 & 75 & 19 & 7 \\
\hline 2000 & 73 & 19 & 8 \\
\hline \hline
\end{tabular}


A repetência também aumenta os custos da educação. A uma taxa de progressão de $73 \%$, as salas de aula de $1^{\mathrm{a}}$ a $4^{\mathrm{a}}$ série terão $16 \%$ mais alunos que com taxas de fluxo perfeitas - e isso com $44 \%$ dos alunos jamais terminando a escola.

No ensino médio a situação é semelhante, mas as taxas de evasão são mais altas. Isso é de se esperar, uma vez que alunos deste nível são mais velhos, e, portanto, o mercado de trabalho está mais aberto à sua participação.

Altamente preocupante é que as taxas de repetência caíram mais ou menos rapidamente até meados da década de 90, mas depois estagnaram nos níveis muito altos mostrados acima.

A dificuldade de calcular as taxas de fluxo não é um problema grave do ponto de vista analítico, uma vez que duas outras estatísticas fáceis de calcular caracterizam perfeitamente o fluxo escolar: a taxa de matrícula líquida e a distorção idadesérie. Isto sugere um método fácil de exibir ambos ao mesmo tempo: um diagrama de fase pode mostrar a co-evolução das duas variáveis no tempo.

A Figura 6 mostra no eixo vertical a taxa de matrícula líquida e no eixo horizontal o nível de distorção idade-série no final de cada ciclo educacional. Cada cruz representa a matrícula de $1^{\mathrm{a}}$ a $4^{\mathrm{a}}$ série e a distorção idade-série na $4^{\mathrm{a}}$ série em um dado ano no período 1981 a 2004; cada círculo representa a matrícula de $5^{\mathrm{a}}$ a $8^{\mathrm{a}}$ série e a distorção idade-série no final da $8^{\mathrm{a}}$ em um dado ano. Movimentos para cima e para a esquerda representam melhorias na situação educacional; movimentos para baixo e para direita representam pioras. Movimentos na diagonal para cima-direita ou para baixoesquerda representam melhorias na matrícula à custa da distorção e na distorção à custa da matrícula, respectivamente.

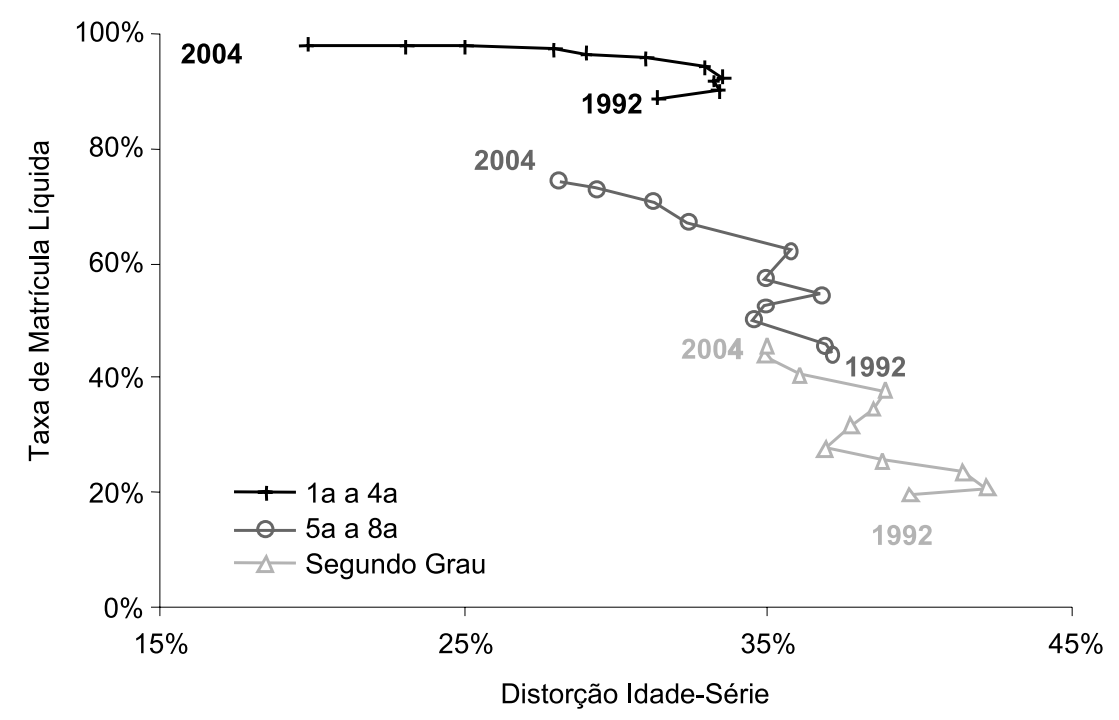

Figura 6 - Diagrama de fase matrícula líquida distorção idade-série

Fonte: Microdados Pnad.

A figura também mostra que de $1^{\mathrm{a}}$ a $4^{\mathrm{a}}$ série o movimento se concentrou na redução da distorção idade-série, enquanto de $5^{\mathrm{a}}$ a $8^{\mathrm{a}}$ série o aumento na matrícula foi maior. Talvez isto se deva ao fato de a matrícula em 1981 de $5^{\mathrm{a}}$ a $8^{\mathrm{a}}$ série ser de pífios $31 \%$. Outro fato visível em ambos os grupos de séries é que as melhorias se deram mais na década de noventa, principalmente a partir da segunda metade, do que na década de oitenta. Esta diferença entre os períodos é particularmente visível nas séries de $5^{\mathrm{a}}$ a $8^{\mathrm{a}}$, onde o aumento na taxa líquida de matrícula é de nove pontos percentuais durante os nove anos que separam 1981 de 1990, contra 23 pontos nos nove que separam 1992 de 2001. Felizmente, tudo indica que esta tendência vem se mantendo na presente década.

Este tipo de diagrama é também útil, pois permite visualizar as desigualdades educacionais ao fornecer representações 
do desempenho para grupos diferentes, tais como quintos de renda ou regiões do País, representações estas que se encontram nos dois painéis da Figura 7.

Os resultados por região são claros: o Nordeste mostra um comportamento diferente das outras regiões. Enquanto nas outras regiões o progresso vem ocorrendo tanto na distorção como no acesso desde 1981, na Região Nordeste quase todo o progresso até 1999 foi devido ao acesso, e apenas a partir de então a distorção começou a cair. Ademais, não há uma convergência visível entre a Região Nordeste e as outras. Já entre as Regiões Sul, Sudeste e Centro-Oeste a convergência é visível, sendo o comportamento da Região Centro-Oeste especialmente notável. A diferença entre as matrículas líquidas das Regiões Sudeste e Centro-Oeste cai de 33 pontos percentuais em 1981 para 0,6 ponto em 2004. A queda

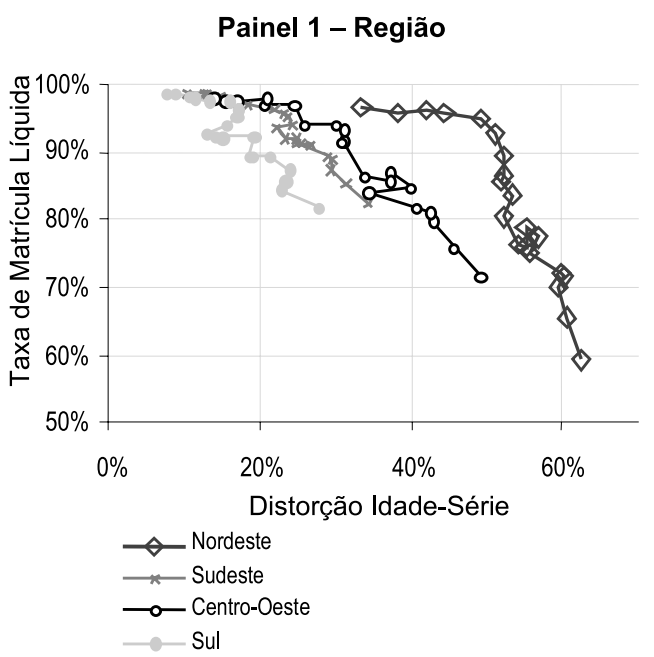

na diferença das porcentagens de alunos defasados com dois anos ou mais foi de cinco para dois pontos percentuais.

Em termos de renda, as diferenças também são claras. O quinto mais alto já tinha boas taxas de acesso em 1981 e quase toda a melhoria foi na redução da distorção, que hoje é de 9\%. Em outras palavras, para o quinto de renda mais alta da população, não há muito como melhorar o fluxo de $1^{\mathrm{a}}$ a $4^{\mathrm{a}}$ série, e quase todo o esforço hoje deveria ser centrado na melhoria da qualidade educacional. Já no quinto mais pobre as taxas de acesso em 1981 eram de meros 54\%. O progresso foi impressionante, e, hoje, 95\% das crianças do quinto mais pobre se encontram na escola, porém mais que um terço deles continua defasado em dois anos ou mais, o que demonstra que persistem desafios no fluxo e na qualidade do ensino.

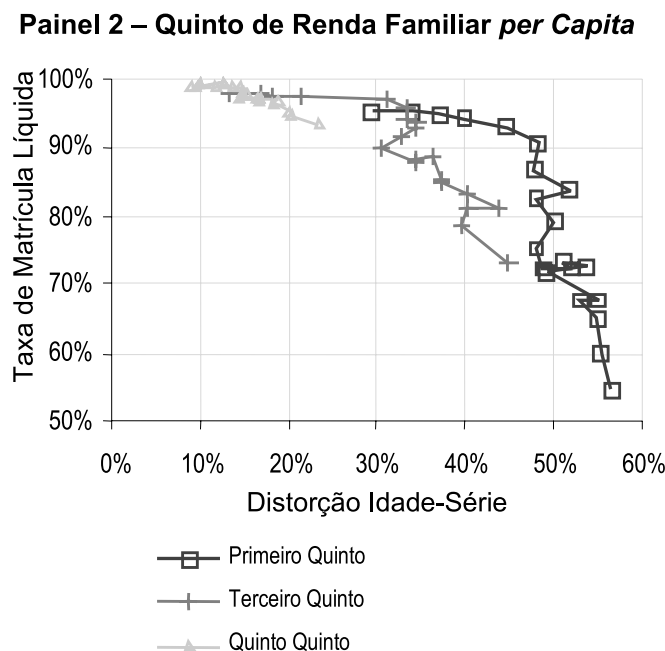

Figura 7 - Diagrama de fase matrícula líquida distorção idade-série - primeiro ciclo do ensino fundamental ( $1^{\mathrm{a}}$ a $4^{\mathrm{a}}$ série)

Finalmente, a convergência das curvas sugere que o ensino de $1^{\mathrm{a}}$ a $4^{\mathrm{a}}$ série tem se tornado mais eqüitativo no Brasil. Enquanto todos os quintos de renda viram a proporção de suas crianças em situação de alta distorção idade-série, o quinto de renda menor também viu a proporção de suas crianças fora da escola cair drasticamente. Em termos regionais, a convergência é menos clara, devido às fortes defasagens ainda observadas entre o Nordeste e as outras regiões.

Os dois painéis da Figura 8 mostram os mesmos dados para as últimas quatro séries do ensino fundamental. Os gráficos mostram uma melhora lenta, mas constante, tanto no acesso como na distorção. Seguindo a evolução por quinto de renda, não se vê a convergência que era visível para $1^{\mathrm{a}}$ a $4^{\mathrm{a}}$ série. Ao contrário, parece que o quinto mais pobre passa no mesmo espaço matrícula-distorção que o terceiro quinto passou uma década antes e que este segue, com 10 a 15 anos de atraso, o padrão do quinto mais rico. Todos os quintos aumentam a taxa de matrícula em um ritmo mais ou menos duas vezes superior àquele ao qual reduzem a distorção. 
Em termos regionais, alguma convergência entre as Regiões Sul, Sudeste e Centro-Oeste parece visível, principalmente entre as duas primeiras. Não se vê diferença nas taxas de matrícula entre essas regiões, e a diferença nas taxas de distorção cai de onze pontos percentuais em 1981 para nove em 1990 e para um pouco mais que quatro em 2004. Já as diferenças entre as Regiões Sul e Nordeste permanecem intactas em 30 pontos percentuais na distorção e entre 20 e 30 pontos na matrícula.

O contraste entre a clara convergência entre classes de renda e regiões no primeiro ciclo e a falta de convergência no segundo ciclo do ensino fundamental parece

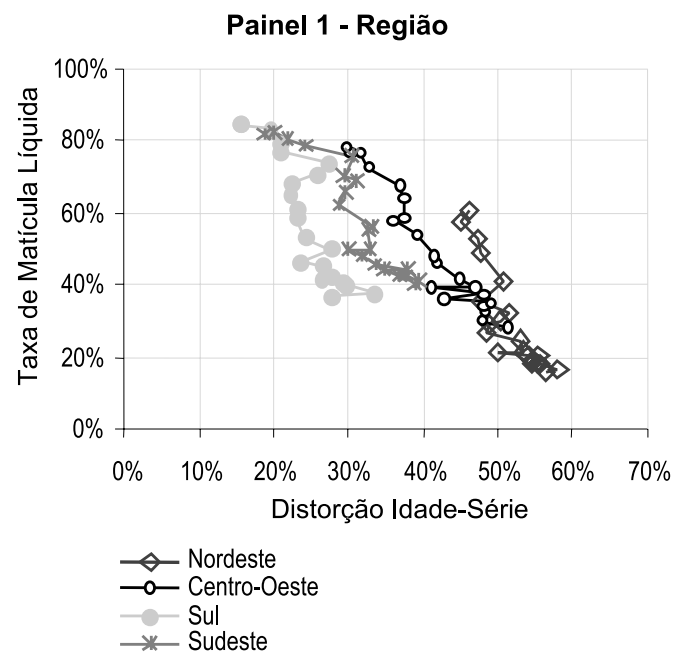

paradoxal. Parte da explicação se encontra em efeitos de coorte: os alunos que entram no ensino melhorando nas primeiras quatro séries só entram nas quatro seguintes quatro anos (ou mais) depois. No entanto, diferenças qualitativas que duram 22 anos não podem ser explicadas por efeitos de geração. Creio que demonstra como a medida legal que define o ensino fundamental forma uma unidade de oito (ou nove) séries não se impõe à realidade e existe considerável evasão entre o primeiro e o segundo ciclo. Finalmente, os dados acima mostram que o acesso ao segundo ciclo do fundamental continua um forte desafio para a política educacional.

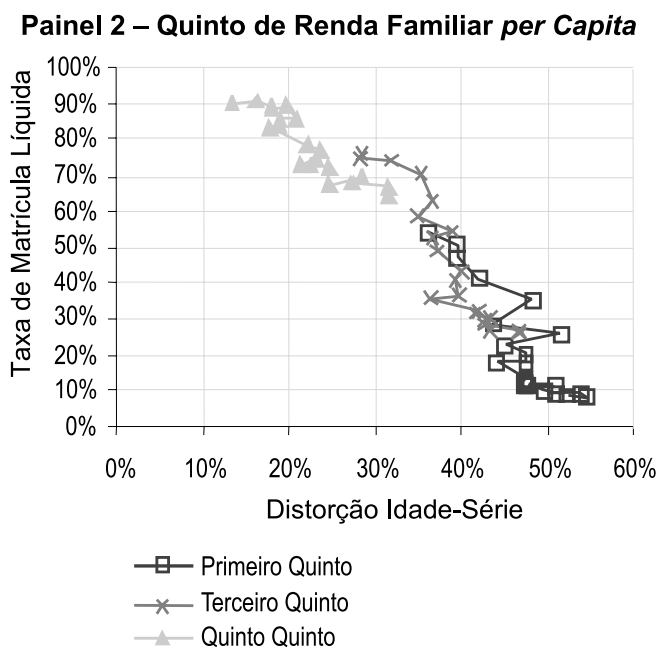

Figura 8 - Diagrama de fase matrícula líquida distorção idade-série - Segundo ciclo do ensino fundamental ( $5^{\mathrm{a}}$ a $8^{\mathrm{a}}$ série $)$

\section{Aprendizado}

Além de estar em salas de aula e passar de ano, os alunos do sistema educacional precisam aprender conteúdo. É evidente que o domínio de conteúdo acadêmico não é o único objetivo do sistema educacional e que o aprendizado de valores e atitudes e a experiência de socialização podem ser considerados tão importantes quanto o aprendizado acadêmico. Entretanto, escolas que não ensinam a ler e escrever simplesmente não são defensáveis.

O Brasil conta com um sistema de avaliação de conteúdo acadêmico excelente. O Instituto Nacional de Estudos e Pesquisas Educacionais Anísio Teixeira (Inep) avalia o domínio de conteúdo em cada ano impar, desde 1995, utilizando provas padronizadas com base na Teoria de Resposta ao Item. Esta avaliação bienal se chama Sistema de Avaliação do Ensino Básico (Saeb) e segue os padrões mais rigorosos de qualidade. Os resultados, comparáveis tanto entre séries como entre anos, são bastante robustos, com exceção de um ano. Neste sentido, o Saeb é um excelente termômetro de domínio de conteúdo.

A Figura 9 mostra a distribuição $a c u-$ mulada das notas do Saeb em 2003, para a $4^{\mathrm{a}}$ série do ensino fundamental, em comunicação escrita. A distribuição pode ser lida do seguinte modo: as linhas horizontais leves mostram diferentes níveis de proficiência medida e, também, o que 
representam no eixo da proficiência acadêmica (o eixo vertical). ${ }^{4}$ Cada ponto no eixo horizontal representa uma porcentagem dos alunos de 2003, e a curva, que porcentagem dos alunos obtém uma dada proficiência na prova. Por exemplo, a curva intercepta a linha de 200 pontos, que corresponde a um nível básico de proficiência, na altura 75 , o que quer dizer que $75 \%$ dos alunos da $4^{\mathrm{a}}$ série em 2003 foram incapazes de demonstrar competências de linguagem básicas e $25 \%$ alcançaram ou excederam este nível. O nível básico de proficiência em linguagem corresponde à habilidade de encontrar informações secundárias em textos, relacionar expressões ou idéias que lidam com o mesmo tema ou fazer inferências globais de um texto. Em outras palavras, este nível de proficiência é o necessário para ler e entender um artigo simples de jornal.

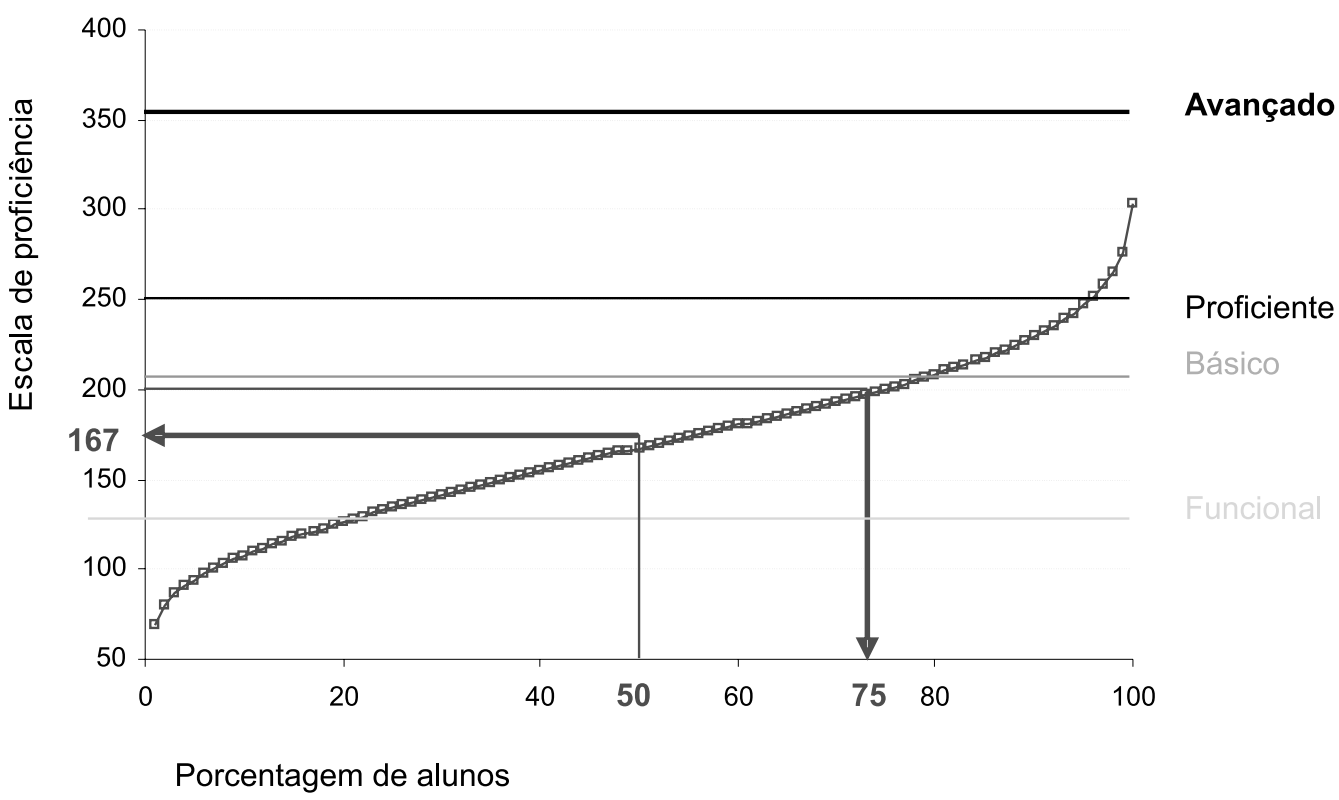

\section{Figura 9 - Distribuição acumulada de proficiência em linguagem de alunos da $4^{\mathrm{a}}$ série do ensino fundamental em 2003 \\ Fonte: SAEB microdados.}

A figura pode também ser lida na direção inversa. Se uma posição no eixo horizontal é desejada - por exemplo, a mediana -, a proficiência correspondente pode ser identificada com ajuda da distribuição acumulada. No caso da Figura 9, a mediana corresponde à nota 167. Este nível não é um ponto interpretado da escala do Saeb e, portanto, não pode ser descrito como a capacidade de ler um artigo de jornal ou qualquer outra capacidade definida. No entanto, é possível inferir que o aluno mediano de $4^{\mathrm{a}}$ série em 2003 se encontrava entre o nível básico e o nível funcional, definido como a proficiência necessária para localizar informações centrais em textos básicos.

Qualquer que seja a direção na qual a distribuição acumulada acima é lida, a conclusão não é alentadora: os alunos de $4^{\mathrm{a}}$ série têm domínio de conteúdo bastante limitado no Brasil. Isto quer dizer que as escolas brasileiras não têm sido eficazes em ensinar conteúdos a seus alunos.

Além de mensurar o conhecimento dos alunos nas $4^{\mathrm{a}}$ e $8^{\mathrm{a}}$ séries do ensino fundamental e na $3^{\mathrm{a}}$ série do ensino médio, o Saeb permite comparar o conhecimento em dois pontos no tempo. A equalização das notas entre anos não é tarefa fácil e existe a possibilidade de erro de equalização, mas, caso não haja erro de equalização, é possível saber se os alunos sabem mais ou menos em dois momentos no tempo. Deste modo, se uma curva da distribuição encontra-se acima de outra, pode-se dizer que, para qualquer centésimo, os alunos representados pela curva de cima têm resultados superiores aos seus pares na curva de baixo. Quando isto ocorre, dizemos que a curva de cima domina em primeira ordem curva de baixo. 

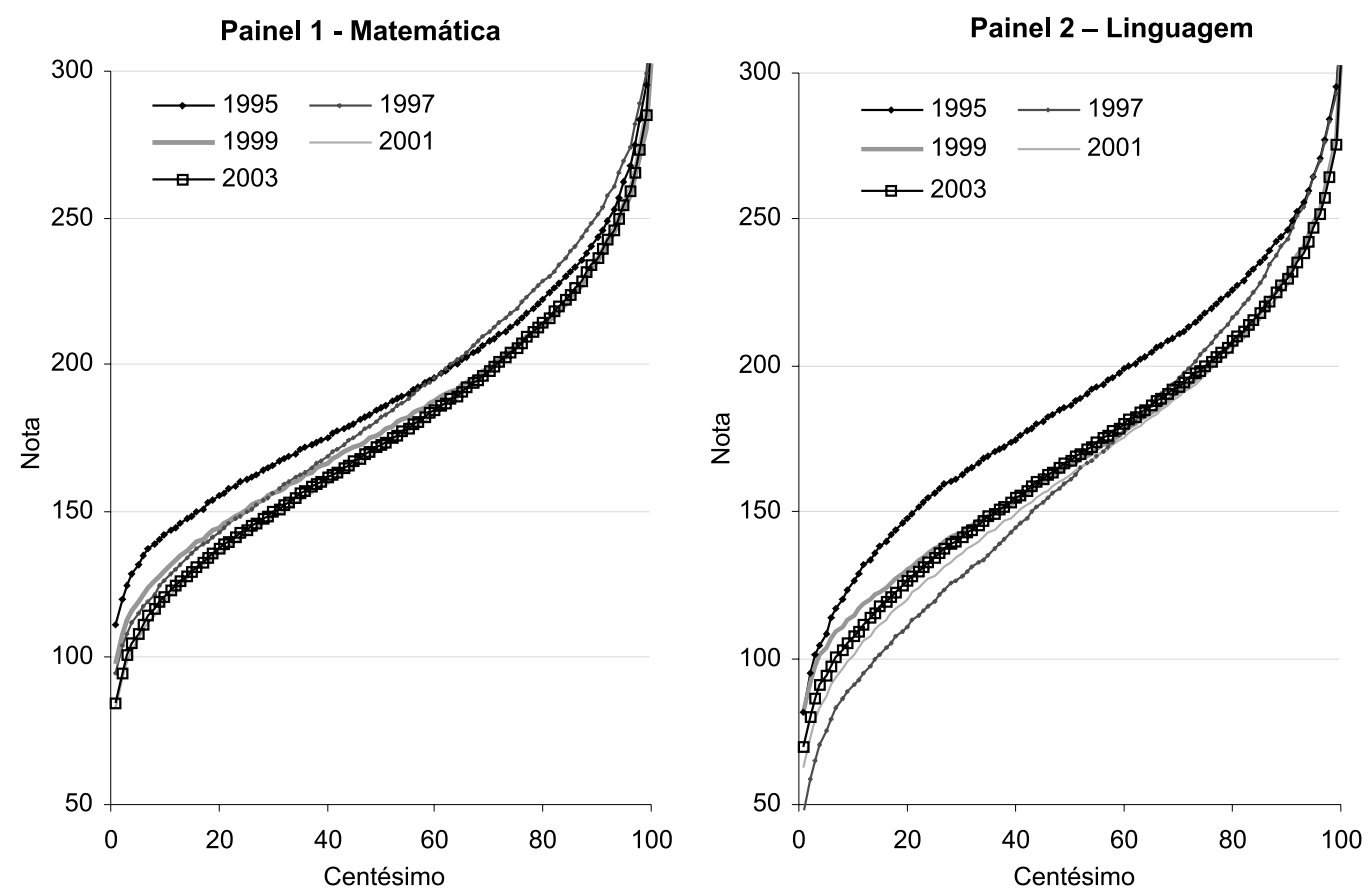

Figura 10 - Distribuição acumulada da $4^{\text {a }}$ série do ensino fundamental

Fonte: Saeb microdados.

O Painel 2 da Figura 10 mostra que os resultados em Linguagem, de 1995, dominam em primeira ordem todos os anos posteriores. Entre os anos posteriores não há relações de dominância, e todas as curvas se interceptam ao redor do centésimo 60. Em Matemática, a queda é menos dramática, mas a curva de 1995 domina todos os anos posteriores, salvo 1997. Em outras palavras, pode-se afirmar que o conhecimento dos nossos alunos já baixo em 1995, diminuiu em 1997 e nunca mais se recuperou. Antes que esta constatação sirva como sentença condenatória do nosso sistema educacional, é importante lembrar que ele ampliou a taxa de matrícula líquida de $1^{\mathrm{a}}$ a $4^{\mathrm{a}}$ série em quase seis pontos percentuais e reduziu a distorção idade-série em mais que dez. Isto quer dizer que uma porcentagem maior das nossas crianças está ingressando na escola e, destas, uma porcentagem maior chega à $4^{\mathrm{a}}$ série e tem suas competências medidas. Esses alunos, é evidente, vêm dos estratos sociais menos favorecidos. Em outras palavras, a origem socioeconômica dos alunos que ingressam nas nossas escolas vem caindo não por ação ou inação do sistema educacional, e sim pela inclusão educacional. É claro que o esforço necessário para incluir estas crianças sem perda de qualidade não foi feito ou foi infrutífero, uma vez que educar é a grande responsabilidade da escola, independentemente da origem socioeconômica dos seus alunos.

Qual foi o tamanho da queda? Para responder a esta pergunta pode-se usar o ponto interpretado da Figura 9 - a competência básica que permite ler e compreender um texto simples de jornal. Lê-se diretamente no gráfico que a porcentagem de alunos da $4^{\mathrm{a}}$ série que têm esta habilidade caiu de $38 \%$ para $25 \%$. Em Matemática o ponto interpretado é 175 , que corresponde à capacidade de resolver problemas simples envolvendo adição e subtração e o reconhecimento de figuras geométricas elementares. De 1995 a 2003, a porcentagem de alunos atingindo este nível de proficiência caiu de $60 \%$ para $48 \%$ das crianças matriculadas na $4^{a}$ série. Antes de interpretar este resultado como sendo melhor que o de Linguagem, cabe lembrar que, em 2003, um em cada dois alunos da $4^{\text {a }}$ série não consegue associar os nomes "triângulo" e "círculo” às respectivas formas geométricas. 

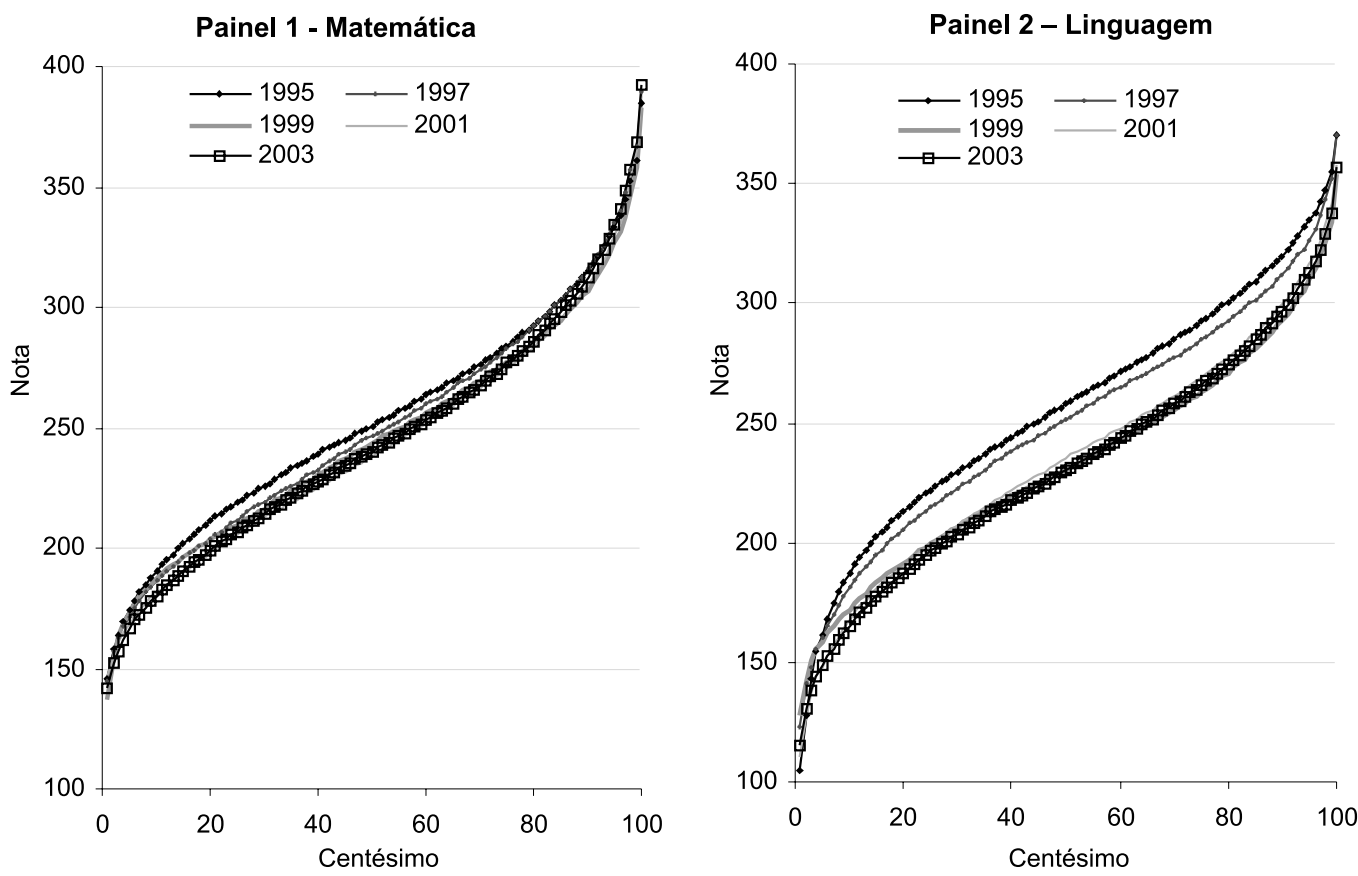

Figura 11 - Distribuição acumulada da $8^{\mathrm{a}}$ série do ensino fundamental

Fonte: Saeb microdados.

A Teoria de Resposta ao Item permite também que comparações sejam feitas entre séries. A Tabela 11 mostra que a diferença média entre a $4^{\mathrm{a}}$ e a $8^{\mathrm{a}}$ séries em 2003 é de 63 pontos em Linguagem e 68 em Matemática, o que equivale a um aprendizado médio anual de 16 pontos em Linguagem e 17 em Matemática. Considerando as quedas registradas nas médias da $4^{\mathrm{a}}$ série, entre 1995 e 2003, de 19 e 13 pontos em Linguagem e Matemática, respectivamente, chega-se, com uma regra de três, ao resultado de que os alunos se atrasaram, em média, um ano e dois meses em Linguagem e nove meses em Matemática. É claro que este tipo de brincadeira numérica é um abuso conceitual, e as escalas de proficiência não foram desenhadas para serem manipuladas deste modo, mas pelo menos temos assim uma intuição do tamanho da queda no aprendizado demonstrado pelos alunos.

Os painéis da Figura 11 mostram que o aprendizado medido na $8^{\mathrm{a}}$ série segue mais ou menos o mesmo comportamento que o aprendizado medido na $4^{\mathrm{a}}$ série. Há quedas maiores em Linguagem e menores em Matemática, mas, em ambas, são significativas. A grande diferença entre as tendências na $8^{\mathrm{a}} \mathrm{e}$ na $4^{\mathrm{a}}$ séries é que, enquanto na $4^{\mathrm{a}}$ a grande queda ocorre de 1995 para 1997, na $8^{\mathrm{a}}$ esta queda é maior de 1997 para 1999. Como as lógicas demográficas subjacentes são as mesmas, não demorarei mais neste ponto.

Tabela 11 - Médias das proficiências do Saeb em Matemática e Linguagem

\begin{tabular}{|l|c|c|c|c|c|} 
& 1995 & 1997 & 1999 & 2001 & 2003 \\
\hline Média & 188 & 165 & 171 & 165 & 169 \\
\hline Mediana & 187 & 162 & 166 & 163 & 168 \\
\hline & \multicolumn{5}{|c|}{ Comunicação-4 } \\
\hline Média & 256 & 250 & 233 & 235 & 232 \\
\hline Mediana & 258 & 252 & 230 & 235 & 230 \\
\hline
\end{tabular}

\begin{tabular}{|c|c|c|c|c|}
\hline 1995 & 1997 & 1999 & 2001 & 2003 \\
\hline \multicolumn{5}{|c|}{ Matemática - $4^{\mathrm{a}}$ Série } \\
\hline 191 & 187 & 181 & 176 & 177 \\
\hline 185 & 182 & 177 & 171 & 173 \\
\hline \multicolumn{5}{|c|}{ Matemática - $8^{a}$ Série } \\
\hline 253 & 250 & 246 & 243 & 245 \\
\hline 251 & 247 & 244 & 238 & 240 \\
\hline
\end{tabular}

Fonte: Saeb microdados 
Um ponto extremamente controverso é a possibilidade de erro de cálculo na construção das equivalências de 1995 para 1997 em Linguagem. O tamanho da queda é muito grande e não faz parte de padrão observado de 1997, que é de quedas muito menores ou estabilidade e não é acompanhado em magnitude pelos resultados em Matemática. O que é mais curioso ainda é que esta queda foi observada também na rede privada, onde não existem os fatores demográficos decorrentes da melhora no acesso e no fluxo. Dada a complexidade do procedimento e o fato de que o País estava ainda aperfeiçoando seu sistema de medição da qualidade, não é impossível que isto tenha acontecido. Por outro lado, as tendências em outros anos, outras séries e outras matérias deixam claro que o movimento no período foi de queda ou no máximo estabilidade em um patamar baixo do aprendizado dos alunos.

O Brasil participa de duas avaliações de qualidade internacionais: o Laboratório Latino-Americano de Avaliação da Qualidade da Educação (LLECE) e o Programme for International Student Assessment (Pisa). Na primeira, ficamos na média dos 11 países que dela participaram, próximos do Peru e do México, mas muito abaixo de Cuba, Uruguai ou Argentina. Na segunda, ficamos em último, entre 43 países, em todas as matérias avaliadas no ano de 2000. Em 2003, ficamos em 40 (na frente apenas do Peru) em Matemática e em 37 em Linguagem (na frente do Peru, México, Indonésia e Tunísia).

Para deixar algum espaço para o otimismo, a interpretação de que a queda observada estaria sendo gerada principalmente pela inclusão educacional tardia sugere que os resultados devam parar de cair em breve. Observamos que, na $4^{\mathrm{a}}$ série, houve aumento na proficiência média medida pelo Saeb de 2001 para 2003, apesar de as quedas continuarem na $8^{\mathrm{a}}$. Nossa melhoria no Pisa também foi considerável: não apenas saímos do incomodo último lugar como também houve aumento nas notas.

\section{O ensino médio}

Jovens de 15 a 17 anos compõem um grupo etário particularmente difícil. É nesta idade que a maioria faz a transição do mundo da escola para o mundo do trabalho; é esta idade que acompanha a maior vulnerabilidade à entrada no crime ou à morte violenta; é nesta idade que os indivíduos começam a pensar em constituir suas próprias famílias e assumir o peso da responsabilidade adulta. É também nesta idade que se encontra a barreira seletiva mais forte e temida do processo educacional: o vestibular. Não é surpreendente que a adolescência seja um período tão difícil.

\section{Onde se encontram os jovens de 15 a 17 anos?}

A maioria dos jovens dessa faixa etária nem trabalha nem procura trabalho, mas a sua participação no mercado de trabalho começa a tornar-se uma realidade. Embora boa parte dos jovens esteja empregada, esta situação ainda é minoritária. A maior parte se encontra na escola, e um em quatro tem tanto trabalho como estudo em suas vidas. Um em cada dois jovens estuda sem trabalhar.

A Tabela 13 mostra a freqüência escolar dos jovens de 15 a 17 anos por ciclo escolar. Trinta e nove em cada cem não se encontram sequer no ensino médio e se arrastam através das oito séries do ensino fundamental. Destes, $12 \%$ ainda estão nas quatro primeiras séries. Que alguém com 15 anos ou mais ainda tenta terminar

Tabela 12 - jovens de 15 a 17 anos por freqüência à escola e participação no mercado de trabalho

\begin{tabular}{|c|c|c|c|}
\hline \multicolumn{1}{|c|}{ Situações } & Na Escola & Fora da Escola & Total \\
\hline No Mercado de Trabalho & $29,6 \%$ & $9,8 \%$ & $39,4 \%$ \\
\hline Fora do Mercado de Trabalho & $52,8 \%$ & $7,8 \%$ & $60,6 \%$ \\
\hline Total & $\mathbf{8 2 , 4 \%}$ & $\mathbf{1 7 , 6 \%}$ & $\mathbf{1 0 0 , 0} \%$ \\
\hline
\end{tabular}

Fonte: Pnad 2003. 
Tabela 13 - Jovens de 15 a 17 anos por nível educacional

\begin{tabular}{|l|c|}
\hline \multicolumn{1}{|c|}{ Nível } & $\mathbf{1 5}$ a $\mathbf{1 7}$ Anos \\
\hline Fundamental (Primeiro Ciclo) & $4,7 \%$ \\
\hline Fundamental (Segundo Ciclo) & $34,6 \%$ \\
\hline Médio & $37,7 \%$ \\
\hline Educação Especial & $0,5 \%$ \\
\hline EJA & $4,9 \%$ \\
\hline Fora da Escola & $17,6 \%$ \\
\hline \multicolumn{1}{|c|}{ Total } & $100,0 \%$ \\
\hline
\end{tabular}

Fonte: Pnad 2003 e Censo Escolar 2003.

o primeiro ciclo do fundamental é mostra da extraordinária tenacidade desses meninos e meninas, mesmo em face das condições de aprendizado extremamente adversas. Pode também indicar as poucas perspectivas de vida para um jovem entrando no mercado de trabalho sem o ensino fundamental completo.

A elevada matrícula no ensino fundamental, juntamente com os $17,6 \%$ que já evadiram, deixa apenas $37,7 \%$ dos jovens de 15 a 17 anos onde deveriam estar: matriculados no ensino médio. A Tabela 13 não mostra, mas boa parte destes está com alguma distorção idade-série. Além disso, 75,2\% dos $17,6 \%$ que evadiram o fizeram sem completar o fundamental e outros $20,1 \%$, sem completar o médio. Em outras palavras, estes jovens não se encontram fora da escola por terem completado o nível de ensino desejado e sim por estarem exauridos por múltiplas repetências.

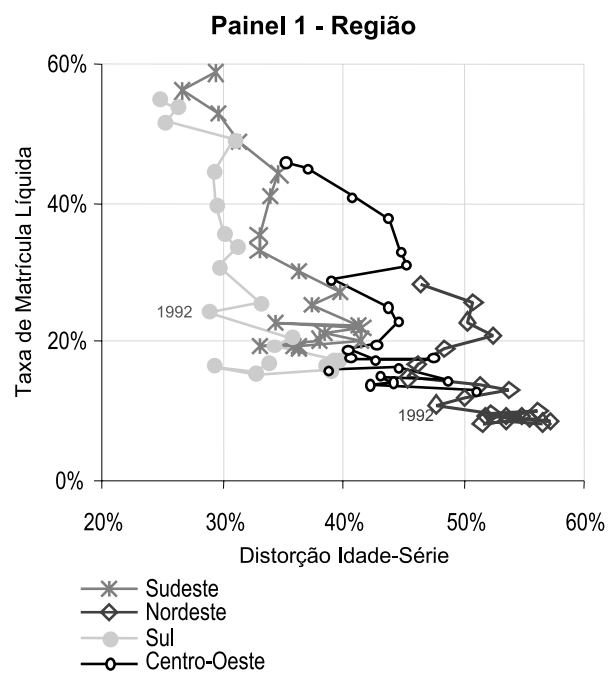

\section{Taxas de matrícula e distorção idade-série}

É possível fazer para o ensino médio os mesmo diagramas de fase já apresentados na Figura 5. Os dois painéis da Figura 12 mostram a evolução das taxas de matrícula líquida e de distorção idade-série na $3^{\mathrm{a}}$ série do ensino médio, por região e por quinto de renda. Embora as figuras não sejam tão límpidas quanto as figuras para os ciclos anteriores, uma coisa fica clara: a trajetória nestes últimos 20 anos tem sido de melhoria e divergência. O Painel 1 mostra que de 1981 a 1992 não houve qualquer melhoria na Região Nordeste e que de 1992 a 2004 a região começou a melhorar lentamente, principalmente quanto à taxa de matrícula. Em comparação, as Regiões Sul e Sudeste mostraram melhoria lenta até 1992 seguida de uma melhoria rápida, aumentando assim as distâncias com a Região Nordeste.

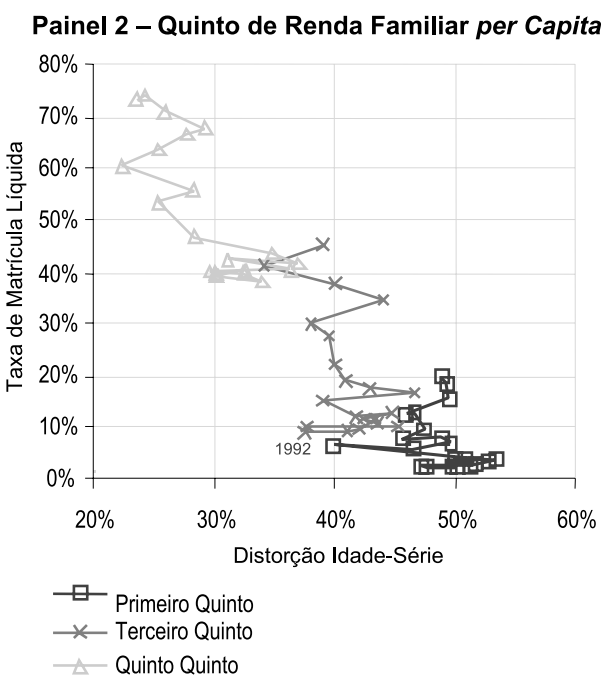

Figura 12 - Diagrama de fase matrícula líquida distorção idade-Série - Ensino Médio Fonte: Pnads. 
O mesmo comportamento é ainda mais forte com relação aos quintos de renda: enquanto em 1981 as diferenças entre o primeiro e o quinto eram de 17 pontos em distorção e 38 em acesso, em 2004 tinham aumentado para $25 \mathrm{em}$ e $53 \mathrm{em}$ acesso. O mesmo fenômeno visível com relação ao diagrama de fase de $5^{\mathrm{a}}$ a $8^{\mathrm{a}}$ série é ainda mais forte no ensino médio - as três curvas parecem partes de uma mesma trajetória, só que com cerca de 15 anos de diferença. Se assim for, podemos afirmar que os indivíduos do primeiro quinto estão onde estavam os do último quinto há 30 anos ou mais. Não sei dizer se esta constatação é otimista ou pessimista.

\section{Aprendizado}

Em termos de aprendizado, o Saeb mostra uma evolução semelhante ao que é visto no caso das séries inferiores. A Figura 13 mostra que há pouca variação nas distribuições das proficiências em Matemática e uma queda na distribuição de proficiências em Linguagem. Cabe ressaltar, no entanto, que isto ocorre em um contexto de aumento considerável de matrícula, que ocorre menos nas séries inferiores. No ensino médio, a matrícula segundo o Censo Escolar quase que dobrou, de 5,3 milhões em 1995 para 9 milhões em 2004. Conforme a já conhecida perversa dinâmica educacional das nossas escolas, esses alunos adicionais serão de origem socioeconômica inferior aos que se encontravam na escola antes de 1995. Ou seja, dado que os resultados não caíram essencialmente nada em Matemática e a queda se conteve em Linguagem, é provável que o ensino médio tenha melhorado no País.
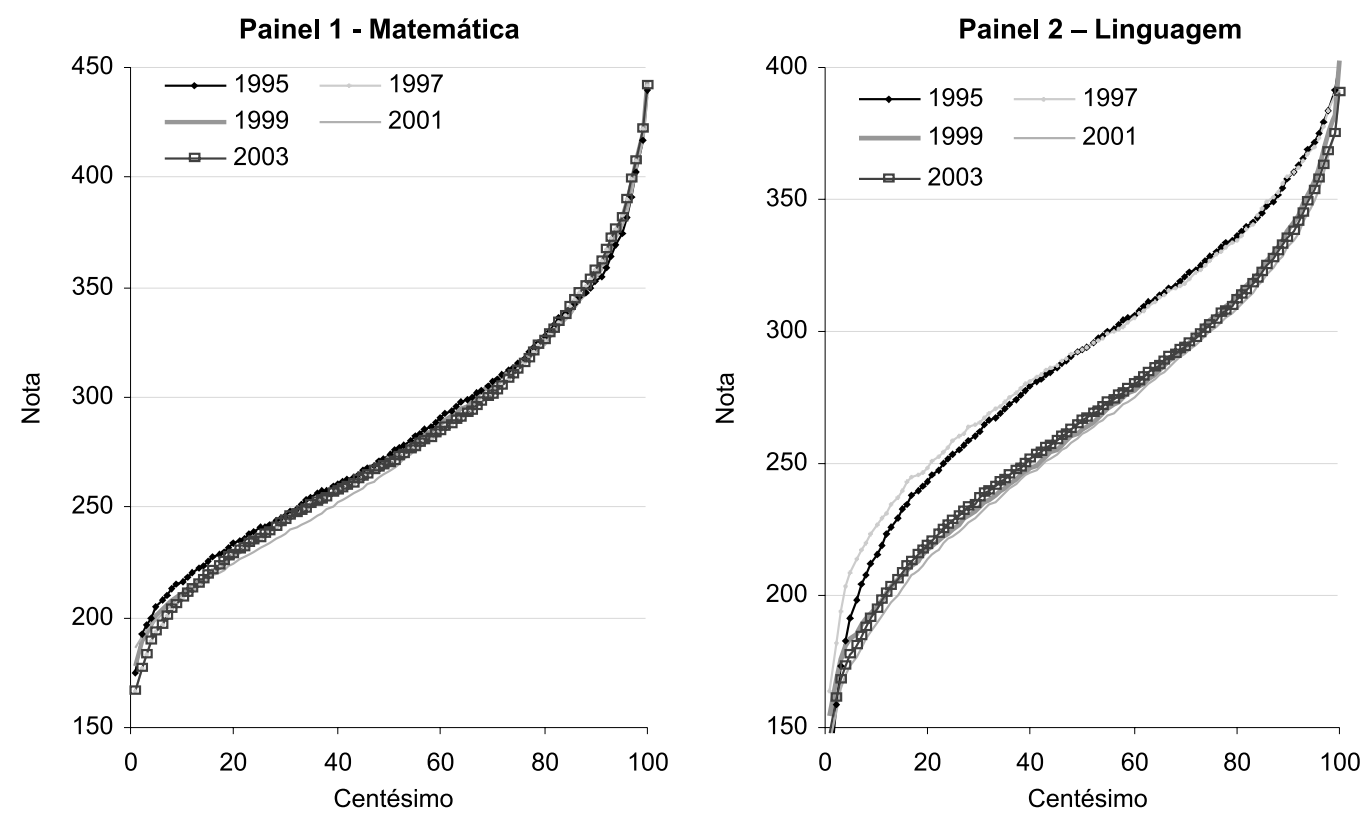

Figura 13 - Distribuição acumulada da $3^{\text {a }}$ série do ensino médio

Fonte: Saeb microdados.

Apesar da boa notícia referente à nãoqueda dos resultados do Saeb, as comparações internacionais ainda são pouco elogiosas para o País. Como foi dito na seção anterior, o Brasil participa da avaliação internacional de maior alcance que há - o Pisa. Como os sistemas educacionais não são totalmente comparáveis entre si no que tange a sua organização, a população avaliada pelo Pisa é o conjunto de todas as crianças escolarizadas de 16 anos.
A Figura 14 mostra os resultados no Pisa 2003 para vários países, por categoria de proficiência. São seis categorias e um grupamento adicional que são os que estão abaixo da categoria 1. Estes são alunos que sequer conseguiram entender a prova e cujas respostas não diferem significativamente de um padrão aleatório.

Como era de se esperar, o Brasil se sai particularmente mal nesta avaliação, uma 
vez que nossa repetência faz com que a população de 16 anos esteja matriculada predominantemente em série e grau abaixo do esperado. $\mathrm{O}$ resultado disto é que comparamos populações no meio do ensino médio em países com pouca repetência com uma população onde metade ainda está no fundamental, no Brasil. Apesar de uma melhoria significativa de 2000 para 2003, encontramo-nos ainda com muito atraso com relação a outros países, como a Figura 14 deixa claro.

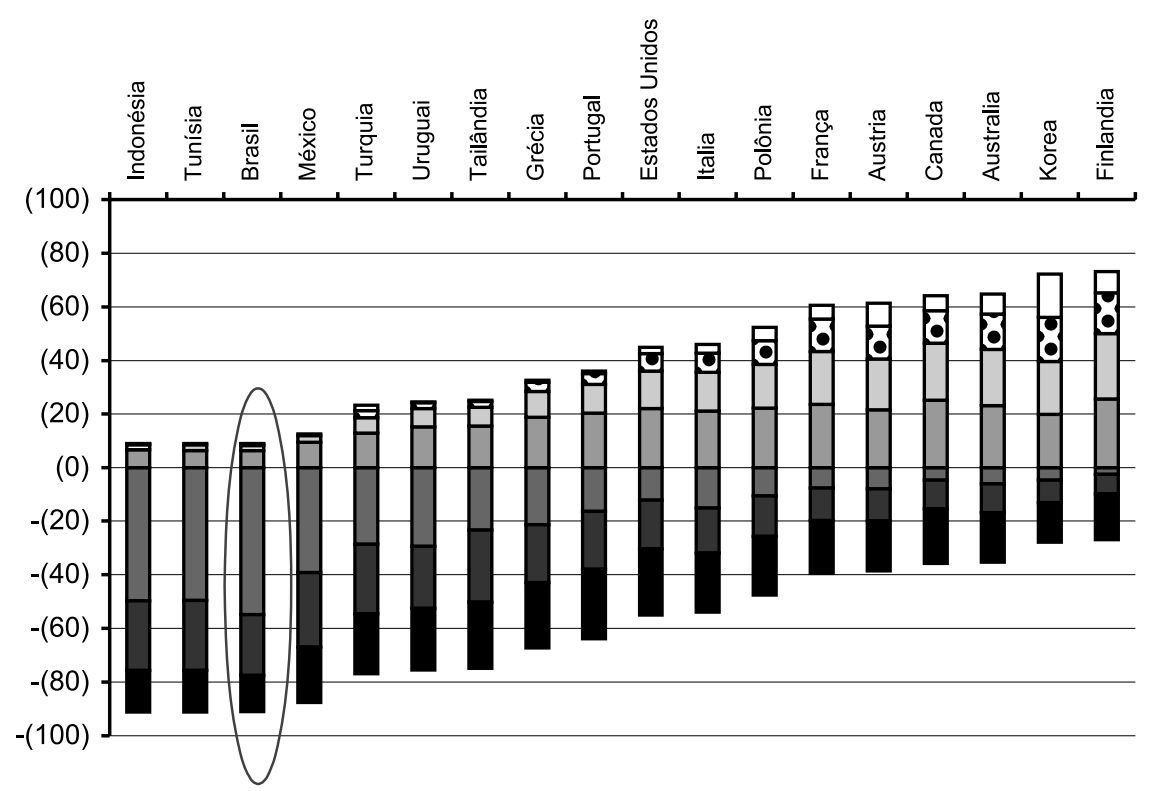

Figura 14 - Distribuição das notas do Pisa por categoria de proficiência Fonte: Pisa/OECD.

\section{Ensino superior e ensino de jovens e adultos}

O forte processo de seleção divide o grupo etário de 18 a 25 anos em dois subgrupos educacionais muito diferentes. De um lado estão os indivíduos matriculados em instituições de ensino superior, na sua maioria oriundos de famílias privilegiadas. Do outro lado está um grande grupo de pessoas que, exauridos pela má qualidade da escola e repetência, se encontram ainda na educação básica, muitos ainda no fundamental, seja via abandono do processo educacional formal com posterior reingresso, seja via acúmulo de vários anos repetidos.

\section{O que fazem os indivíduos de 18 a 25 anos no Brasil?}

A Tabela 14 mostra que a maioria dos indivíduos de 18 a 25 anos, no Brasil, já se encontra fora da escola e no mercado de trabalho. O trabalho e sua busca já é uma realidade para quase três quartos desses jovens. Sessenta e um em cada cem (61\%) desses jovens já trabalham, e outros 12,8\% procuram trabalho. Estes números indicam uma taxa de desemprego de $17,3 \%$, o que faz do mercado de trabalho um espaço não muito atrativo para esses jovens.

A segunda categoria mais comum na Tabela 14 é a de jovens que não se encontram na escola, não estão trabalhando e nem procuram trabalho - trata-se de uma situação particularmente preocupante. Um pouco menos de metade $(41,3 \%)$ desses jovens são cônjuges que potencialmente escolheram ou aceitaram as atividades domésticas em detrimento do engajamento no mercado de trabalho, mas a maioria não está nesta situação. O que as estatísticas mostram são jovens totalmente sem perspectivas na vida: não freqüentam escola, não têm emprego e já perderam as esperanças de um dia encontrar trabalho; e os jovens, 
em oposição às jovens, não têm como casar, por não poder sustentar uma família. Um pouco mais de metade $(52,5 \%)$ deste grupo não completou o ensino fundamental e outros 19\% não têm diploma do ensino médio, o que limita seriamente suas opções no mercado de trabalho. É difícil ver que opções um jovem nesta categoria tem, além da marginalidade econômica ou social.

Tabela 14 - Jovens e adultos de 18 a 25 anos

\begin{tabular}{|c|c|c|c|}
\hline Situações & Na Escola & Fora da Escola & Total \\
\hline No Mercado de Trabalho & $20,9 \%$ & $53,0 \%$ & $73,9 \%$ \\
\hline Fora do Mercado de Trabalho & $11,0 \%$ & $15,1 \%$ & $26,1 \%$ \\
\hline Total & $\mathbf{3 1 , 9 \%}$ & $\mathbf{6 8 , 1} \%$ & $\mathbf{1 0 0 , 0} \%$ \\
\hline
\end{tabular}

Fonte: Microdados Pnad 2003.

A Tabela 15 mostra o nível educacional alcançado pelo grupo de 18 a 25 anos como um todo. Por um lado, um em cada dez está cursando o ensino superior e outros $2 \%$ já o terminaram; por outro lado, $6 \%$ ainda cursam o fundamental e outros $40 \%$ estão fora da escola, com fundamental ou menos.
Outros $13 \%$ terminaram o fundamental, mas não o ensino médio. Este quadro mostra o fracasso do sistema educacional que estes jovens freqüentaram, em levá-los a obter níveis educacionais condizentes com as exigências da economia do século 21 .

Tabela 15 - Nível de instrução alcançado por jovens e adultos de 18 a 25 anos

\begin{tabular}{|lcc|}
\hline \multicolumn{1}{c}{ Ciclo escolar } & \multicolumn{2}{c|}{ Na escola e fora } \\
\hline Fora da escola & Todos juntos & Separados \\
\hline Sem instrução e menos de 1 ano & $3 \%$ & $5 \%$ \\
\hline Primeiro ciclo do fundamental incompleto & $6 \%$ & $8 \%$ \\
\hline Primeiro ciclo do fundamental & $19 \%$ & $27 \%$ \\
\hline Fundamental completo & $13 \%$ & $18 \%$ \\
\hline Ensino médio & $26 \%$ & $38 \%$ \\
\hline Superior Completo & $2 \%$ & $3 \%$ \\
\hline Total & $68 \%$ & $100 \%$ \\
\hline Na escola & & $1 \%$ \\
\hline Alfabetização de adultos & $0 \%$ & $4 \%$ \\
\hline Primeiro ciclo do fundamental & $1 \%$ & $15 \%$ \\
\hline Segundo ciclo do fundamental & $5 \%$ & $1 \%$ \\
\hline Outro fundamental & $0 \%$ & $46 \%$ \\
\hline Médio & $15 \%$ & $33 \%$ \\
\hline Superior, inclusive mestrado e doutorado & $10 \%$ & $100 \%$ \\
\hline Total & $32 \%$ & \\
\hline & $100 \%$ & \\
\hline
\end{tabular}

Fonte: Pnad 2003. 
Estas estatísticas não refletem plenamente as melhorias que ocorreram no sistema educacional nos anos noventa. Os jovens que tinham de 18 a 25 anos em 2003 ingressaram no sistema educacional formal entre 1985 e 1992. A coorte que terá de 18 a 25 anos em 2010 deverá mostrar resultados melhores. No entanto, esta coorte pode ser descrita como a "geração perdida”, que não teve como aproveitar o mercado de trabalho fácil dos anos do "milagre" nem o sistema escolar algo melhorado dos anos noventa. As perspectivas de inserção dessa geração no mercado de trabalho têm sido particularmente sombrias, principalmente para aqueles que não terminaram o ensino médio.

A Tabela 16 mostra os rendimentos totais para duas coortes de idade: os que têm de 18 a 25 anos e os que têm de 26 a 30 anos. O rendimento é calculado por nível de escolaridade e de acordo com o percentil na distribuição de rendimento daquele nível. $\mathrm{O}$ grupo de idade de 26 a 30 anos é também apresentado para mostrar o que os indivíduos que hoje têm de 18 a 25 anos podem esperar no futuro próximo. Os resultados não são animadores para os que têm baixos níveis de escolaridade.

Tabela 16 - Rendimento total de adultos ocupados por grupo de idade, segundo o nível de escolaridade e percentil

\begin{tabular}{|l|c|c|c|c|c|c|c|}
\hline \multirow{2}{*}{ Escolaridade } & \multicolumn{3}{|c|}{ Indivíduos ocupados de 18 a 25 } & \multicolumn{3}{c|}{ Indivíduos ocupados de 26 a 30 } \\
\cline { 2 - 7 } & Percentil 10 & Mediana & Percentil 90 & Percentil 10 & Mediana & Percentil 90 \\
\hline $\begin{array}{l}\text { Primário } \\
\text { incompleto }\end{array}$ & 0 & 220 & 450 & 20 & 247 & 600 \\
\hline $\begin{array}{l}\text { Primário } \\
\text { completo }\end{array}$ & 0 & 250 & 540 & 130 & 390 & 900 \\
\hline $\begin{array}{l}\text { Secundário } \\
\begin{array}{l}\text { Superior } \\
\text { completo }\end{array}\end{array}$ & 150 & 380 & 802 & 240 & 500 & 1.300 \\
\hline
\end{tabular}

Os rendimentos medianos para trabalhadores de 26 a 30 anos com menos de ensino médio não são altos: $\mathrm{R} \$ 200$ para os que não têm sequer o fundamental e R\$350 para os que têm apenas o fundamental completo. Mais preocupante é que estes indivíduos também se encontram em situação de risco salarial e podem obter salários muito baixos: os indivíduos no décimo percentil da distribuição de rendimentos dos com fundamental incompleto ganham meros $\mathrm{R} \$ 20$, e os do décimo percentil dos que têm fundamental completo ganham $\mathrm{R} \$ 130$. Ou seja, quem é jovem e tem escolaridade baixa no Brasil vive em constante risco de cair na pobreza.

Os fatos pouco animadores mostrados na Tabela 16 não passam despercebidos entre os jovens de 18 a 25 anos. A explosão nos anos noventa da demanda por Educação de Jovens e Adultos (EJA), cuja oferta pelo sistema educacional é grosseiramente insuficiente, é um sinal disso. Apenas 30\% dos 5,2 milhões que cursavam a educação básica estavam matriculados em EJA - a grande maioria freqüenta a escola em turmas com alunos muito mais jovens e que não usam metodologias apropriadas para jovens adultos. As turmas de EJA são um pouco maiores, mas poderiam facilmente acomodar mais alunos, se usassem abordagens pedagógicas adequadas. Finalmente, o fato de $43 \%$ da matrícula de jovens de 18 a 25 anos estar no ensino médio regular aponta para uma organização inadequada deste nível de aprendizado.

Um dos desafios mais importantes nos próximos anos é uma oferta escolar adequada para indivíduos no grupo de idade de 18 a 25 anos. Apesar da matrícula em EJA ter aumentado de 2,8 milhões em 1997 para 4,4 milhões em 2003, o fato disto cobrir apenas 30\% do grupo etário relevante mostra a inadequação da oferta. Situações onde um jovem de 18 a 25 anos pode aprender tão bem em uma sala de aula regular como freqüentando EJA são possíveis, mas a necessidade de combinar o estudo com trabalho e responsabilidades familiares e as diferenças etárias na sala de aula fazem com que estas situações sejam a exceção e não a regra. 


\section{Ensino superior}

No outro extremo do espectro socioeconômico estão os indivíduos matriculados na educação superior. Um primeiro problema de análise é acertar os dados de matrícula. De acordo com a Pnad de 2003, 4,35 milhões de indivíduos freqüentam o ensino superior no Brasil; destes, 2,69 milhões tinham entre 18 e 25 anos de idade. ${ }^{5}$ Já o Censo da Educação Superior do mesmo ano conta 3,89 milhões de alunos, o que implica uma discrepância de $12 \%$ entre as duas fontes. Não há explicação aparente para este fato, e, normalmente, pesquisas domiciliares e registros administrativos mostram maior concordância. A Figura 15 mostra que esta discrepância ocorre a partir de 1999, uma vez que os números em anos anteriores estão muito próximos dos dados do Inep. Em qualquer caso, ela mostra o crescimento vertiginoso das matriculas, qualquer que seja a fonte.

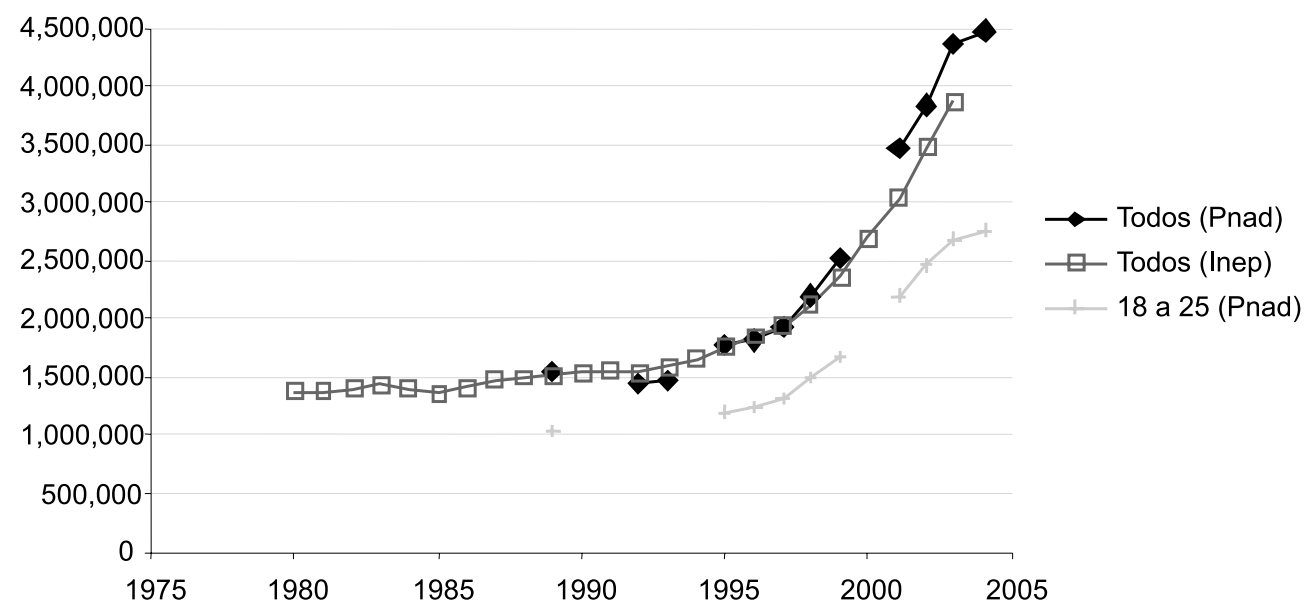

Figura 15 - Matrícula de graduação nas instituições de ensino superior

Fonte: Pnad e Inep/Censo do Ensino Superior.

O crescimento mostrado na Figura 15 é resultado de uma conspiração de inúmeros fatores. Do lado demográfico, como foi visto nas Tabelas 1 a 4, o grupo de 18 a 25 anos é um dos que têm maior taxa de crescimento - e isto vai continuar. Enquanto a população de 7 a 17 anos caiu 1\% de 1996 a 2000 , a de 18 a 25 anos cresceu em $12 \%$.

Do lado do fluxo escolar, as melhorias acumuladas em acesso e fluxo em níveis anteriores, também documentados neste texto, têm levado a aumentos grandes no tamanho das coortes terminando o ensino médio. Estes fatores levaram o número de indivíduos que fazem o vestibular a aumentar de 1,8 milhões em 1992 para 4 milhões em 2000 e quase 5 milhões em 2003.

A Figura 15 mostra como o sistema de educação superior respondeu a esta explosão na demanda por vagas. Enquanto as instituições privadas multiplicavam sua oferta, as públicas respondiam com maior lentidão, e as instituições federais de ensino superior foram particularmente lentas na sua resposta. Esta tendência intensifica-se de 1998 em diante.

A Tabela 17 mostra os mesmos dados desagregados por tipo de instituição. Enquanto de 1980 a 1995 o crescimento total do sistema foi de $28 \%$, o observado no período de 1995 a 2003 foi de 55\%. Enquanto de 1980 a 1995 as novas matrículas foram acomodadas de modo mais ou menos igual nas redes públicas (principalmente estadual) e privada, de 1995 a 2003 a rede privada abriu $80 \%$ das novas vagas. Em 1985, 59\% da matrícula se encontrava em universidades privadas; em 2003 esta porcentagem tinha subido para $71 \%$.

Não há nenhuma razão inerente para preocupar-se com o fato de instituições privadas absorverem $78 \%$ do aumento na demanda por ensino superior. Nada faz com que universidades privadas sejam essencialmente inferiores às públicas, e em outros níveis de ensino exatamente o oposto ocorre.

\footnotetext{
A Pnad de 2004 contabiliza 4,48 milhões no ensino superior, sendo que 2,75 têm entre 18 e 25 anos. Os dados do Censo do Ensino Superior, no entanto, estão disponíveis apenas até 2003. É verdade que os resultados da Pnad expressos em números absolutos não são muito confiáveis.
} 
Tabela 17 - Matrícula por tipo de instituição

\begin{tabular}{|c|c|c|c|c|}
\hline Ano & Total & Federal & $\begin{array}{c}\text { Estadual e } \\
\text { Municipal }\end{array}$ & Privada \\
\hline 1980 & 1.378 & 317 & 176 & 885 \\
\hline 1985 & 1.368 & 327 & 230 & 811 \\
\hline 1990 & 1.540 & 309 & 270 & 961 \\
\hline 1995 & 1.760 & 368 & 333 & 1.059 \\
\hline 2003 & 3.887 & 567 & 570 & 2.750 \\
\hline $80-85$ & & Taxa de Crescimento & & \\
\hline $85-90$ & 172 & 10 & 54 & -74 \\
\hline $90-95$ & 220 & -18 & 40 & 150 \\
\hline $95-03$ & 2.127 & 59 & 63 & 98 \\
\hline $80-95$ & & 199 & 237 & 1.691 \\
\hline $95-03$ & $28 \%$ & Taxa de Crescimento & & $80 \%$ \\
\hline $95-03$ & $55 \%$ & $16 \%$ & $89 \%$ & $20 \%$ \\
\hline
\end{tabular}

Fonte: Inep. Censo da Educação Superior.

A razão pela qual devemos nos inquietar com a acomodação do aumento na demanda por ensino superior nas instituições privadas se encontra na Tabela
18, que mostra a distribuição de cursos, ponderados pela sua matrícula, no ensino superior, por nota recebida no Exame Nacional de Cursos - o Provão.

Tabela 18 - Cursos de ensino superior, por nota no provão, 2000, ponderado pela matrícula

\begin{tabular}{|c|c|c|c|}
\hline Conceito & Federal & $\begin{array}{c}\text { Estadual } \\
\text { Municipal }\end{array}$ & Privada \\
\hline A & $35 \%$ & $17 \%$ & $5 \%$ \\
\hline B & $29 \%$ & $19 \%$ & $14 \%$ \\
\hline C & $24 \%$ & $36 \%$ & $47 \%$ \\
\hline D & $8 \%$ & $18 \%$ & $25 \%$ \\
\hline E & $4 \%$ & $11 \%$ & $10 \%$ \\
\hline Total & $100 \%$ & $100 \%$ & $100 \%$ \\
\hline
\end{tabular}

Fonte: Inep

A tabela fala por si, quando mostra que $35 \%$ dos alunos que estudam em instituições privadas o fazem nas que obtêm notas D ou E, contra $12 \%$ das federais; mostra também que $64 \%$ dos alunos que estudam nas Instituições Federais de Ensino Superior o fazem em universidades ou faculdades que obtêm nota A ou B, contra apenas $19 \%$ dos alunos das instituições privadas. 
Mais preocupante ainda é o fato de que, enquanto a qualidade das instituições privadas tem declinado, a qualidade das Ifes tem melhorado. A Tabela 19 mostra que, nos cursos de administração, direito e engenharia civil - os únicos avaliados todos aos anos de 1996 a 2000 -, a porcentagem de alunos das instituições privadas que estuda em universidades e faculdades conceito A e B caiu de $24 \%$ para $20 \%$, enquanto os que fingem que aprendem em instituições D ou E aumentou de 31 para 35 em cada 100 alunos. Ao contrário, nas Ifes, a proporção dos que estudam em centros A ou B aumentou de 57\% para 79\%, e os que estudam em instituições D e E caiu de 33 para 6 em cada 100 alunos nos três cursos acima mencionados.

Tabela 19 - Cursos de ensino superior, por nota no Provão em 2000, ponderado pela matrícula (Administração, Direito e Engenharia Civil)

\begin{tabular}{|c|c|c|c|c|c|}
\hline Conceitos & 1996 & 1997 & 1998 & 1999 & 2000 \\
\hline \multicolumn{6}{|l|}{ Privadas } \\
\hline$A$ e $B$ & $24 \%$ & $22 \%$ & $21 \%$ & $17 \%$ & $20 \%$ \\
\hline C & $45 \%$ & $46 \%$ & $48 \%$ & $48 \%$ & $45 \%$ \\
\hline $\mathrm{D}$ e $\mathrm{E}$ & $31 \%$ & $33 \%$ & $31 \%$ & $35 \%$ & $35 \%$ \\
\hline \multicolumn{6}{|l|}{ Federais } \\
\hline$A$ e $B$ & $57 \%$ & $66 \%$ & $59 \%$ & $79 \%$ & $79 \%$ \\
\hline C & $9 \%$ & $24 \%$ & $16 \%$ & $17 \%$ & $15 \%$ \\
\hline $\mathrm{D}$ e E & $33 \%$ & $10 \%$ & $25 \%$ & $4 \%$ & $6 \%$ \\
\hline
\end{tabular}

Fonte: Inep.

Se os cursos de Engenharia Química, Veterinária e Odontologia são incluídos, é possível fazer o mesmo exercício para o período 1997-2000, e os resultados são semelhantes.

O ensino superior é um assunto extremamente complexo, que envolve ensino, pesquisa e extensão, além de fortes grupos de pressão, tanto nas instituições públicas como privadas. Este texto não é o local adequado para entrar no assunto de modo mais profundo, entretanto os dados permitem duas generalizações: a primeira é que o setor público é de boa qualidade, mas não tem acompanhado a demanda explosiva por vagas no ensino superior; a segunda é que o setor privado, que tem acomodado grande parte desta demanda por vagas, produz egressos que não sabem o que deveriam saber ao saírem do curso. O resultado geral é que o sistema como um todo não acompanha nem as aspirações sociais por ensino superior nem produz a mão-deobra qualificada necessária para o desenvolvimento do País em um mundo cada vez mais tecnologicamente avançado. Outro sinal da falta que faz um maior número de egressos do ensino superior é o aumento dos retornos à educação superior no mercado de trabalho brasileiro durante a última década, conforme documentado em Soares, Servo e Arbache (2001).

\section{A briga pelo cobertor curto}

Um comentário final que deve ser feito em qualquer revisão da educação no Brasil é sobre a alocação de recursos entre os níveis educacionais. Isto porque esta alocação - perversa - de recursos tem impactos fortes sobre os resultados analisados até agora.

A Tabela 20 mostra a divisão de recursos entre os níveis educacionais. A primeira coluna mostra os cálculos do Inep do gasto por aluno em 1998 em cada nível educacional para os três níveis de governo; a segunda mostra a porcentagem que aquele nível congrega do gasto educacional total; e, finalmente, a terceira mostra a renda média dos alunos matriculados naquele nível em 1998.

Alunos matriculados no ensino superior advêm de famílias cuja capacidade 
de investir no seu futuro é mais que três vezes maior que aquela das famílias dos alunos do ensino fundamental. Parte desta diferença decorre do fato de alunos do nível superior serem parte de famílias mais velhas que estão mais bem posicionadas no ciclo de vida, mas a maioria desta diferença decorre da brutal seleção que existe até o final do ensino médio via repetência e, então, na entrada da universidade via o vestibular. Isto quer dizer que o grosso da diferença na tabela anteriormente citada é resultado de reprodução de desigualdades socioeconô-micas de uma geração para a próxima.

Tabela 20 - Gasto educacional por aluno, porcentagem do gasto total e renda domiciliar média, por nível de ensino - 1998

\begin{tabular}{|l|c|c|c|}
\hline \multicolumn{1}{|c|}{ Nível } & $\begin{array}{c}\text { Gasto Educacional } \\
\text { por Aluno }\end{array}$ & $\begin{array}{c}\text { Porcentagem do Gasto } \\
\text { Total }\end{array}$ & $\begin{array}{c}\text { Renda Domiciliar Média } \\
\text { dos Alunos }\end{array}$ \\
\hline Superior & 9.789 & 23 & 841 \\
\hline Médio & 701 & 6 & 311 \\
\hline Fundamental & 668 & 64 & 188 \\
\hline Pré escola & 877 & 8 & 237 \\
\hline TOTAL & $\mathbf{8 7 2}$ & $\mathbf{1 0 0}$ & $\mathbf{2 6 3}$ \\
\hline
\end{tabular}

Fonte: Custos: Inep com base em pesquisa de 1998 do IBGE; renda domiciliar Pnad 1998.

O Estado, por outro lado, investe nos alunos do ensino superior mais de 14 vezes o que investe nos alunos do fundamental. Parte disso reflete diferenças inescapáveis e inerentes no custo de prover ensino fundamental e superior, mas a maioria reflete atenção desigual outorgada aos diferentes níveis de ensino. Estas diferenças de financiamento não têm passado despercebidas pelas famílias mais ricas, que enviam seus filhos a escolas de ensino fundamental e médio privadas, mas depois trocam-nas pelo ensino público ao enviarem seus filhos ao ensino superior.

\section{Conclusão}

Um olhar sobre o processo educativo que leva em conta tanto níveis educacionais como idades é importante em um país com a repetência alta, como o Brasil. Este olhar permite analisar tanto a situação dos alunos em um dado nível como a das crianças e jovens que deveriam estar matriculados neste nível, mas não estão. Este foi justamente o objetivo deste texto fazer uma revisão sucinta de como tem sido a evolução de cada nível de ensino e sua clientela preferencial durante as duas últimas décadas e como se encontram nos primeiros anos deste novo milênio.
Espero que o texto tenha deixado claros os desafios enfrentados por nosso país neste novo milênio:

- Na pré-escola e creche, o grande desafio é como expandir a cobertura incipiente, com alguma garantia de qualidade e eqüidade. São os mais pobres que mais têm a ganhar e que mais precisam de acesso a creches e pré-escola, justamente as crianças das famílias pobres que não têm acesso à educação infantil pública. Uma meta viável é a universalização da pré-escola nas áreas urbanas.

- No ensino fundamental, o desafio é ensinar. Tanto a repetência como os resultados de avaliações padronizadas mostram que as crianças apresentam surpreendente tenacidade ao permanecer em um processo educativo no qual não avançam ano após ano e não aprendem. Dizer que são crianças cuja origem socioeconômica é desfavorecida e que por isso têm dificuldades de aprendizagem é verdadeiro, mas não é desculpa, uma vez que em muitos outros países as crianças de origem socioeconômica desfavorecida também aprendem a ler. 
- Um segundo desafio no ensino fundamental é ampliar a oferta de educação especial ou inclusiva para crianças com deficiências, para que a universalização possa realmente ser atingida de modo pleno.

- No nível médio também existem dois desafios. O primeiro é expandir a cobertura para acomodar a crescente enxurrada de concluintes do fundamental, mas sem queda de qualidade. É impossível fazer isto sem consideráveis recursos adicionais, o que torna a aprovação do Fundeb de importância fundamental para o País.

- O segundo desafio do ensino médio é o resgate da geração "perdida", que entrou no sistema educacional na década de oitenta e hoje tem baixos níveis educacionais que impedem qualquer perspectiva no mercado de trabalho. Estes jovens precisam desesperadamente de oferta de EJA para continuar uma trajetória educacional abortada pela repetência e baixa qualidade do ensino.

- O desafio na educação superior é como expandir o acesso em instituições de qualidade. Isto quer dizer aumentar a oferta das instituições públicas ou melhorar a qualidade da educação oferecida nas instituições privadas.

\section{Referencias bibliográficas}

ALBERNAZ, A.; FERREIRA, F.; FRANCO, C. Qualidade e eqüidade no ensino fundamental brasileiro. Pesquisa e Planejamento Econômico, v. 32, n. 3, 2003.

BARROS, R. Paes de; MENDONÇA, R.; VELOSO, T. Is poverty the main cause of child work in urban Brazil? Rio de Janeiro: Ipea, 1994. (Ipea discussion paper ; n. 351). Disponível em: <www.ipea.gov.br>

CAVALIERI, Claudia H. O Impacto do trabalho infantil sobre o desempenho escolar: uma avaliação para o Brasil metropolitano. 2002. Tese (Doutorado) - EAESP/Fundação Getúlio Vargas, São Paulo, 2002.

The impact of child labor on educational performance: an evaluation of Brazil. In: ANNUAL MEETING OF THE LATIN AMERICAN AND CARIBBEAN ECONOMIC ASSOCIATION (LACEA), 7., 2002, Madrid. Anais... Madri, Spain, 2002. CD-ROM.

FERRÃO, M. E.; BELTRÃO, K. I.; SANTOS, D. P. dos. O impacto da política de nãorepetência no desempenho escolar dos alunos da $4^{\mathrm{a}}$ série. Pesquisa e Planejamento Econômico, v. 32, n. 3, 2003.

FLETCHER, Phillip. As dimensões transversal e longitudinal do modelo profluxo. Brasília: Ministério da Educação e Cultura, 1997. Não publicado.

FRANCO, C.; MANDARINO, M.; ORTIGÃO, M. I. O plano pedagógico de escola e os resultados escolares. Pesquisa e Planejamento Econômico, v. 32, n. 3, 2003.

INSTITUTO NACIONAL DE ESTUDOS E PESQUISAS EDUCACIONAIS ANÍSIO TEIXEIRA (Inep). A Educação no Brasil na Década de 80. Brasília, 2003.

KLEIN, Ruben. Produção e utilização de indicadores educacionais. Brasília: Inep, 1995. Não publicado.

Utilização da Teoria de Resposta ao Item no Sistema Nacional de Avaliação da Educação Básica (SAEB). LNCC, 2002. Não publicado. 
LEMME, Paschoal. O Manifesto dos Pioneiros da Educação Nova e suas repercussões na realidade educacional brasileira. Revista Brasileira de Estudos Pedagógicos, v. 65, n. 150, p. 255-272, 1984.

LOPEZ DE LEON, F.; MENEZES FILHO, N. Reprovação, avanço e evasão escolar no Brasil. Pesquisa e Planejamento Econômico, v. 32, n. 3, 2003.

PAES DE BARROS, R. et al. Determinantes do Desempenho Educacional no Brasil. Rio de Janeiro: Ipea, 2001. (Ipea Discussion Paper ; n. 834). Disponível em: $<$ www.ipea.gov.br $>$.

PAES DE BARROS, Ricardo; MENDONÇA, Rosane. Uma análise dos determinantes do desempenho educacional no Brasil. Rio de Janeiro: Ipea, 1996. Não publicado.

PAES DE BARROS, Ricardo; SANTOS, Eleonora. Consequências de longo prazo do trabalho precoce. In: FAUSTO, A.; CERVINI, R. O trabalho e a rua: crianças e adolescentes no Brasil urbano dos anos 80. Rio de Janeiro: Unicef/Flacso/CBIA, Cortez, 1996.

RIBEIRO, Sérgio Costa. A educação e a inserção do Brasil na modernidade. Cadernos de Pesquisa, n. 84, p. 63-82, fev. 1993.

RIOS-NETTO, E.; CÉSAR, C. C.; RIANI, J. R. Estratificação Escolar e Progressão Escolar por Série no Brasil. Pesquisa e Planejamento Econômico, v. 32, n. 3, 2003.

SOARES, J. F.; CESAR, C. C.; FONSECA, J. A. Desempenho das Escolas de Ensino Médio de Belo Horizonte no Vestibular da UFMG. Revista Brasileira de Estatística, v. 60, n. 213, p. 95-116, 1999.

SOARES, J. F.; MARTINS, M. I.; ASSUNÇÃO, N. B. A. Heterogeneidade Acadêmica dos Alunos Admitidos na UFMG e PUC-MG. Ensaio: Avaliação e Políticas Públicas em Educação, v. 6, n. 18, p. 57-65, 1998.

SOARES, Sergei; SERVO, Luciana M. Santos; ARBACHE, Jorge Saba. O que (não) sabemos sobre a relação entre abertura comercial e mercado de trabalho no Brasil. Brasília: Ipea, 2001. (Ipea Texto de Discussão ; n. 843).

Sergei Suarez Dillon Soares, mestre em Economia pela Universidade de Brasília (UnB), é pesquisador do Instituto de Pesquisa Econômica Aplicada (Ipea).

Recebido em 10 de maio de 2006.

Aprovado em 18 de agosto de 2006. 